ARTICLE

\title{
Transforming carbon dioxide into jet fuel using an organic combustion-synthesized Fe-Mn-K catalyst
}

\author{
Benzhen Yao (1) 1, Tiancun Xiao ${ }^{1 凶}$, Ofentse A. Makgae ${ }^{2}$, Xiangyu Jie (i) ${ }^{1,3}$, Sergio Gonzalez-Cortes (1) ${ }^{1}$, \\ Shaoliang Guan (10) 4,5, Angus I. Kirkland (D) 2,6, Jonathan R. Dilworth (1D) 1, Hamid A. Al-Megren7, \\ Saeed M. Alshihri ${ }^{7}$, Peter J. Dobson ${ }^{8}$, Gari P. Owen ${ }^{9}$, John M. Thomas ${ }^{10,11}$ \& Peter P. Edwards (1) ${ }^{1 凶}$
}

With mounting concerns over climate change, the utilisation or conversion of carbon dioxide into sustainable, synthetic hydrocarbons fuels, most notably for transportation purposes, continues to attract worldwide interest. This is particularly true in the search for sustainable or renewable aviation fuels. These offer considerable potential since, instead of consuming fossil crude oil, the fuels are produced from carbon dioxide using sustainable renewable hydrogen and energy. We report here a synthetic protocol to the fixation of carbon dioxide by converting it directly into aviation jet fuel using novel, inexpensive iron-based catalysts. We prepare the Fe-Mn-K catalyst by the so-called Organic Combustion Method, and the catalyst shows a carbon dioxide conversion through hydrogenation to hydrocarbons in the aviation jet fuel range of $38.2 \%$, with a yield of $17.2 \%$, and a selectivity of $47.8 \%$, and with an attendant low carbon monoxide (5.6\%) and methane selectivity (10.4\%). The conversion reaction also produces light olefins ethylene, propylene, and butenes, totalling a yield of $8.7 \%$, which are important raw materials for the petrochemical industry and are presently also only obtained from fossil crude oil. As this carbon dioxide is extracted from air, and re-emitted from jet fuels when combusted in flight, the overall effect is a carbon-neutral fuel. This contrasts with jet fuels produced from hydrocarbon fossil sources where the combustion process unlocks the fossil carbon and places it into the atmosphere, in longevity, as aerial carbon - carbon dioxide.

\footnotetext{
${ }^{1}$ KACST-Oxford Centre of Excellence in Petrochemicals, Inorganic Chemistry Laboratory, University of Oxford, South Parks Road, Oxford OX1 3QR, UK. ${ }^{2}$ Department of Materials, University of Oxford, Parks Roads, Oxford OX1 3PH, UK. ${ }^{3}$ Merton College, University of Oxford, Merton Street, Oxford OX1 4JD, UK. ${ }^{4}$ Cardiff Catalysis Institute, School of Chemistry, Cardiff University, Cardiff, UK. ${ }^{5}$ Harwell-XPS - The EPSRC National Facility for Photoelectron Spectroscopy, Research Complex at Harwell (RCaH), Didcot Oxon, OX11 OFA, UK. ${ }^{6}$ Electron Physical Sciences Imaging Centre, Diamond Lightsource Ltd., Didcot, Oxford OX11 ODE, UK. ${ }^{7}$ Materials Division, King Abdulaziz City for Science and Technology, Riyadh 11442, Kingdom of Saudi Arabia. ${ }^{8}$ The Queen's College, University of Oxford, Oxford OX14AW, UK. ${ }^{9}$ Annwvyn Solutions, 76 Rochester Avenue, Bromley, Kent BR1 3DW, UK. 10 Department of Materials Science and Metallurgy, University of Cambridge, 27 Charles Babbage Road, Cambridge CB3 OFS, UK. ${ }^{11}$ Deceased: John M. Thomas. ${ }^{凶} \mathrm{email}$ : xiao. tiancun@chem.ox.ac.uk; peter.edwards@chem.ox.ac.uk
} 
or more than a century our industrial society and humankind's prosperity, wealth and well-being, have been based on the combustion of hydrocarbon fossil fuels. However, it is abundantly clear this has disturbed the natural environment by the emission of greenhouse gases, most notably carbon dioxide $\left(\mathrm{CO}_{2}\right)$, nitrous oxide, and methane ${ }^{1}$. Nevertheless, the use of fossil fuels continues to grow with an expected annual increase of $1.3 \%$ to $2030^{2}$, continually exacerbating this problem in the form of climate change Air transport, playing a significant role in the modern world in worldwide social contact, business and marketing, is a recognized source of high $\mathrm{CO}_{2}$ emissions ${ }^{3}$.

Jet fuel, the generic name for the aviation fuels used in gasturbine powered aircraft has as its main components linear and branched alkanes and cycloalkanes with a typical carbon chainlength distribution of $\mathrm{C}_{8}$-to- $\mathrm{C}_{18}$, and where the ideal carbon chain length is $\mathrm{C}_{8}-\mathrm{C}_{16}{ }^{4}$.

Given these recognised environmental concerns, it is now imperative to develop clean, energy-efficient technologies for producing sustainable or renewable aviation fuels ${ }^{5}$.

Converting $\mathrm{CO}_{2}$ into fuels and high value-added chemicals has attracted significant worldwide interest in the past few years, as it not only contributes to mitigating greenhouse gas emissions but also produces valuable chemical commodities ${ }^{6-24}$. As such, $\mathrm{CO}_{2}$ conversion and utilization should be taken both an integral and important part of greenhouse gas control and sustainable development.

Nevertheless, the activation of $\mathrm{CO}_{2}$ is extremely challenging; $\mathrm{CO}_{2}$ is a fully oxidized, thermodynamically stable and chemically inert molecule. Furthermore, hydrocarbon synthesis via the hydrogenation of $\mathrm{CO}_{2}$ usually favours the formation of short-chain, rather than desirable long-chain, hydrocarbons. Hence most of the research in this area have focused on the selective hydrogenation of $\mathrm{CO}_{2}$ to $\mathrm{CH}_{4}$, the oxygenates, $\mathrm{CH}_{3} \mathrm{OH}, \mathrm{HCOOH}$, and light olefins $\left(\mathrm{C}_{2}-\mathrm{C}_{4}\right.$ olefins $)^{22-41}$, There have been limited studies on producing liquid hydrocarbons of molecularity $\mathrm{C}_{5+}{ }^{42-44}$.

There are two ways to convert $\mathrm{CO}_{2}$ to liquid hydrocarbons; an indirect route, which converts $\mathrm{CO}_{2}$ to $\mathrm{CO}$ or methanol and subsequently into liquid hydrocarbons, or the direct $\mathrm{CO}_{2}$ hydrogenation route, which is usually described as a combination of the reduction of $\mathrm{CO}_{2}$ to $\mathrm{CO}$ via the reverse water gas shift (RWGS) reaction and the subsequent hydrogenation of $\mathrm{CO}$ to long-chain hydrocarbons via Fischer-Tropsch synthesis (FTS) ${ }^{45}$. Jet fuel can then be obtained from the products after industrially recognized treatments such as distillation or hydro-isomerization. The second, direct route is generally recognized as being more economical and environmentally acceptable as it involves fewer chemical process steps, and the overall energy consumption for the entire process is lower ${ }^{46}$.

The relevant chemical reactions for hydrocarbon fuel production are:

Hydrogenation of $\mathrm{CO}_{2}$ :

$\mathrm{CO}_{2}+3 \mathrm{H}_{2} \rightleftarrows-\left(\mathrm{CH}_{2}\right)-+2 \mathrm{H}_{2} \mathrm{O}\left(\Delta H_{298}^{0}=-125 \mathrm{~kJ} \mathrm{~mol}^{-1}\right)$;

The RWGS reaction:

$$
\mathrm{CO}_{2}+\mathrm{H}_{2} \rightleftarrows \mathrm{CO}+\mathrm{H}_{2} \mathrm{O}\left(\Delta H_{298}^{0}=+41 \mathrm{~kJ} \mathrm{~mol}^{-1}\right) \text {, and }
$$

The FTS reaction:

$$
\mathrm{CO}+2 \mathrm{H}_{2} \rightleftarrows-\left(\mathrm{CH}_{2}\right)-+\mathrm{H}_{2} \mathrm{O}\left(\Delta H_{298}^{0}=-166 \mathrm{~kJ} \mathrm{~mol}^{-1}\right)
$$

The direct conversion of $\mathrm{CO}_{2}$ into fuels through these various reactions has attracted great attention in recent years, and a compilation of some of these investigations is highlighted in Table 1. However, there are few reports of the direct catalytic conversion of $\mathrm{CO}_{2}$ to jet fuel range hydrocarbons ${ }^{20,47}$. The key to advancing this process is to search for a highly efficient inexpensive catalyst, that can preferentially synthesise the target hydrocarbon range of interest ${ }^{48}$. Iron-based catalysts, widely used in both the RWGS and FTS reactions, are typically prepared by chemical co-precipitation routes, which unfortunately consumes significant amounts of water ${ }^{49-52}$.

In this investigation, we report the preparation of iron-based catalysts using the Organic Combustion Method (OCM) and determined their catalytic performance for the direct and efficient conversion of $\mathrm{CO}_{2}$ to jet fuel range hydrocarbons. In brief, the $\mathrm{Fe}-\mathrm{Mn}-\mathrm{K}$ catalyst shows a $\mathrm{CO}_{2}$ conversion of $38.2 \%$ and selectivity to $\mathrm{C}_{8}-\mathrm{C}_{16}$ hydrocarbons of $47.8 \%$ with a correspondingly

Table 1 Some typical catalysts performance for the direct conversion of $\mathrm{CO}_{2}$ into hydrocarbon fuels; a brief literature overview.

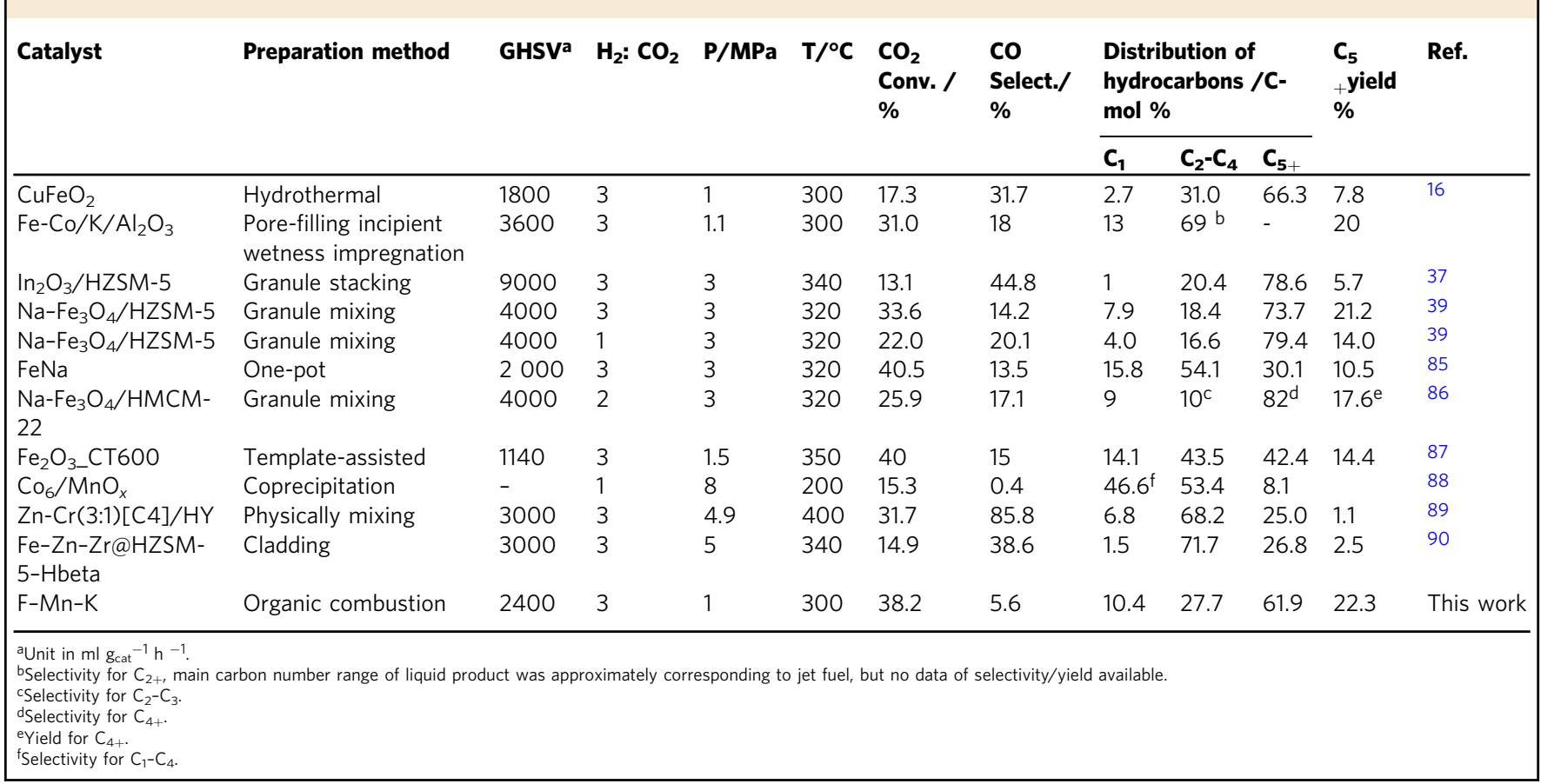



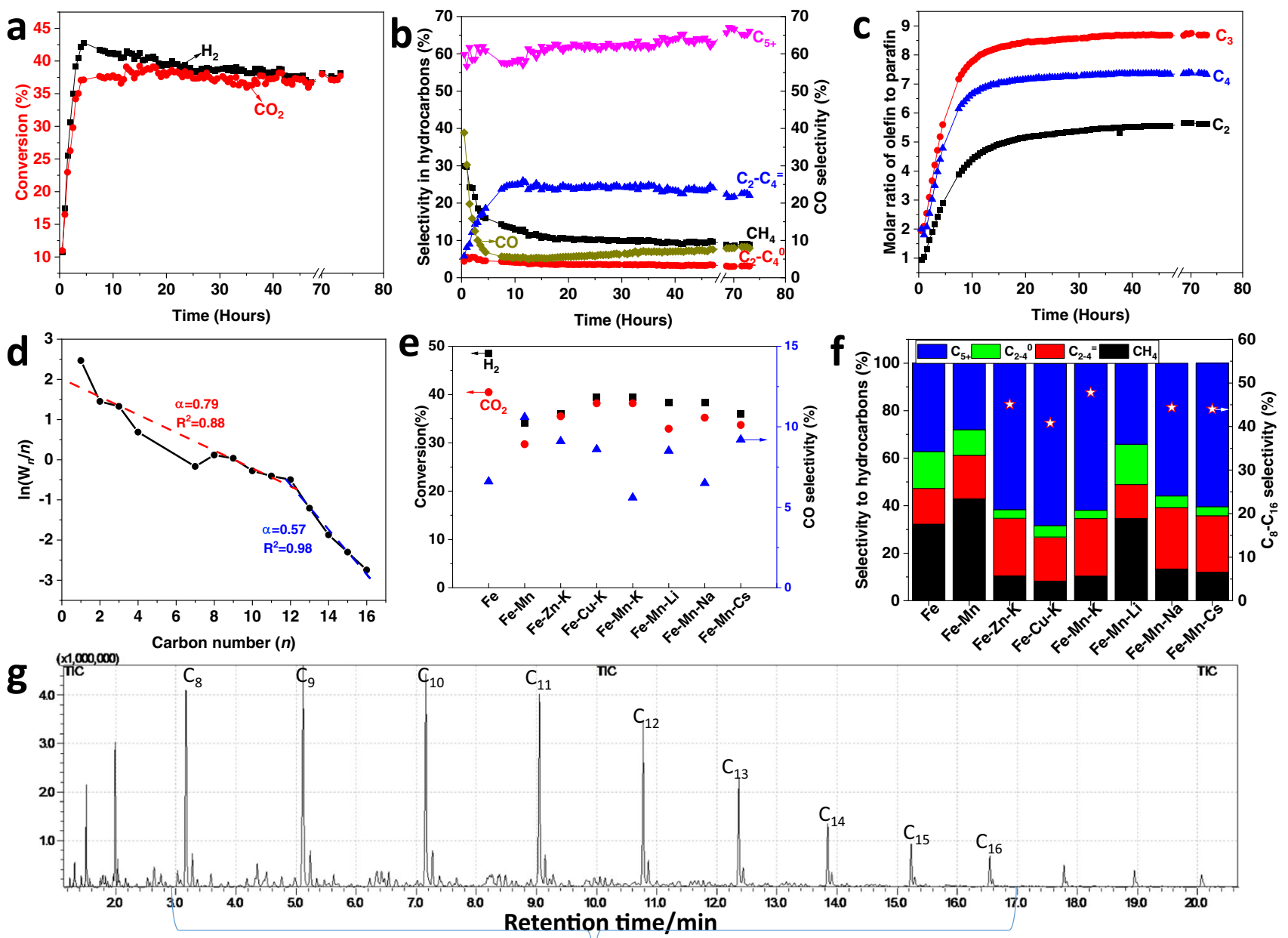

\section{Jet fuel range hydrocarbons $\left(C_{8}-C_{16}\right)$}

Fig. 1 Catalyst performance for the hydrogenation of $\mathbf{C O}_{\mathbf{2}}$ using a $\mathbf{F e}-\mathbf{M n}-\mathbf{K}$ catalyst. a \% conversion of $\mathrm{CO}_{2}$ and $\mathrm{H}_{2}$ as a function of reaction time for the hydrogenation of $\mathrm{CO}_{2}$. b Selectivity of various hydrocarbon products with reaction time for the hydrogenation of $\mathrm{CO}_{2}$. $\mathbf{c}$ Molar ratio of olefin-to-paraffin for the $\mathrm{C}_{2}-\mathrm{C}_{4}$ range with reaction time for the hydrogenation of $\mathrm{CO}_{2}$. $\mathbf{d}$ ASF plot and $\alpha$ values at reaction time of $20 \mathrm{~h}$. e Conversion and $\mathrm{CO}_{2}$ selectivity of $\mathrm{CO}_{2}$ hydrogenation for a reaction time of $20 \mathrm{~h}$ over different catalysts. $\mathbf{f}$ Products selectivities of $\mathrm{CO}_{2}$ hydrogenation for a reaction time of $20 \mathrm{~h}$ over different catalysts. $\mathbf{g}$ GC-MS total ion chromatogram (TIC) of the hydrocarbon fuel from the hydrogenation of $\mathrm{CO}_{2}$ on a Fe-Mn-K catalyst. The jet fuel range hydrocarbons $\left(C_{8}\right.$ to $C_{16}$ ) are shown.

low selectivity for $\mathrm{CH}_{4}$ and $\mathrm{CO}$. In addition, the process also shows a high molar production ratio of olefin-to-paraffin for $\mathrm{C}_{2}-\mathrm{C}_{4}$ hydrocarbons.

\section{Results}

The rising concerns over climate change and the stringent environmental regulations to deplete the utilization of fossilderived fuels have generated great opportunities-and major scientific challenges-on the transformation of $\mathrm{CO}_{2}$ into sustainable, synthetic hydrocarbons fuels, particularly in the synthesis of renewable aviation fuels. At the heart of any progress in this area, the all-important conversion process is closely related to the development of advanced catalysts of high performance for the $\mathrm{CO}_{2}$ hydrogenation reaction. Therefore, the utilization of novel methods of catalyst preparation represents an important strategy to produce advanced catalytic formulations having highperformance levels. Among the catalyst synthesis methods, the so-called OCM is recognized as an energy-efficient and economically viable approach for the one-pot synthesis of a variety of nanostructured solid catalysts. In this method, the utilization of an organic fuel, having also a cation-complexation character, to yield a homogenous redox solution of the different metal precursors is highly advantageous. In addition, a relatively moderate self-sustaining exothermic reaction of the redox gel may be beneficial to produce the necessary nanostructured catalysts with an efficient promoter effect due to the well-controlled aqueous chemistry of the preparation route and ensuing combustion conditions.

The performance of $\mathrm{Fe}-\mathrm{Mn}-\mathrm{K}$ catalysts for the hydrogenation of $\mathrm{CO}_{2}$. In terms of the conversion of $\mathrm{CO}_{2}$ and $\mathrm{H}_{2}$ to hydrocarbons and $\mathrm{CO}$, the product selectivities, the Anderson-Schulz-Flory (ASF) product distribution, together with the molar ratio of olefinto-paraffin ratio for $\mathrm{C}_{2}-\mathrm{C}_{4}$ from the hydrogenation of $\mathrm{CO}_{2}$ using a $\mathrm{Fe}-\mathrm{Mn}-\mathrm{K}$ catalysts, is shown in Fig. 1; specifically, both the conversions and selectivities for $\mathrm{CO}_{2}$ hydrogenation are shown for a reaction time of $20 \mathrm{~h}$ over a variety of Fe-based catalysts. The GCMS spectrum of the collected liquid products from the hydrogenation of $\mathrm{CO}_{2}$ on the catalyst $\mathrm{Fe}-\mathrm{Mn}-\mathrm{K}$ is also shown in Fig. 1g. The GC-FID chromatogram of the gaseous hydrocarbon products 

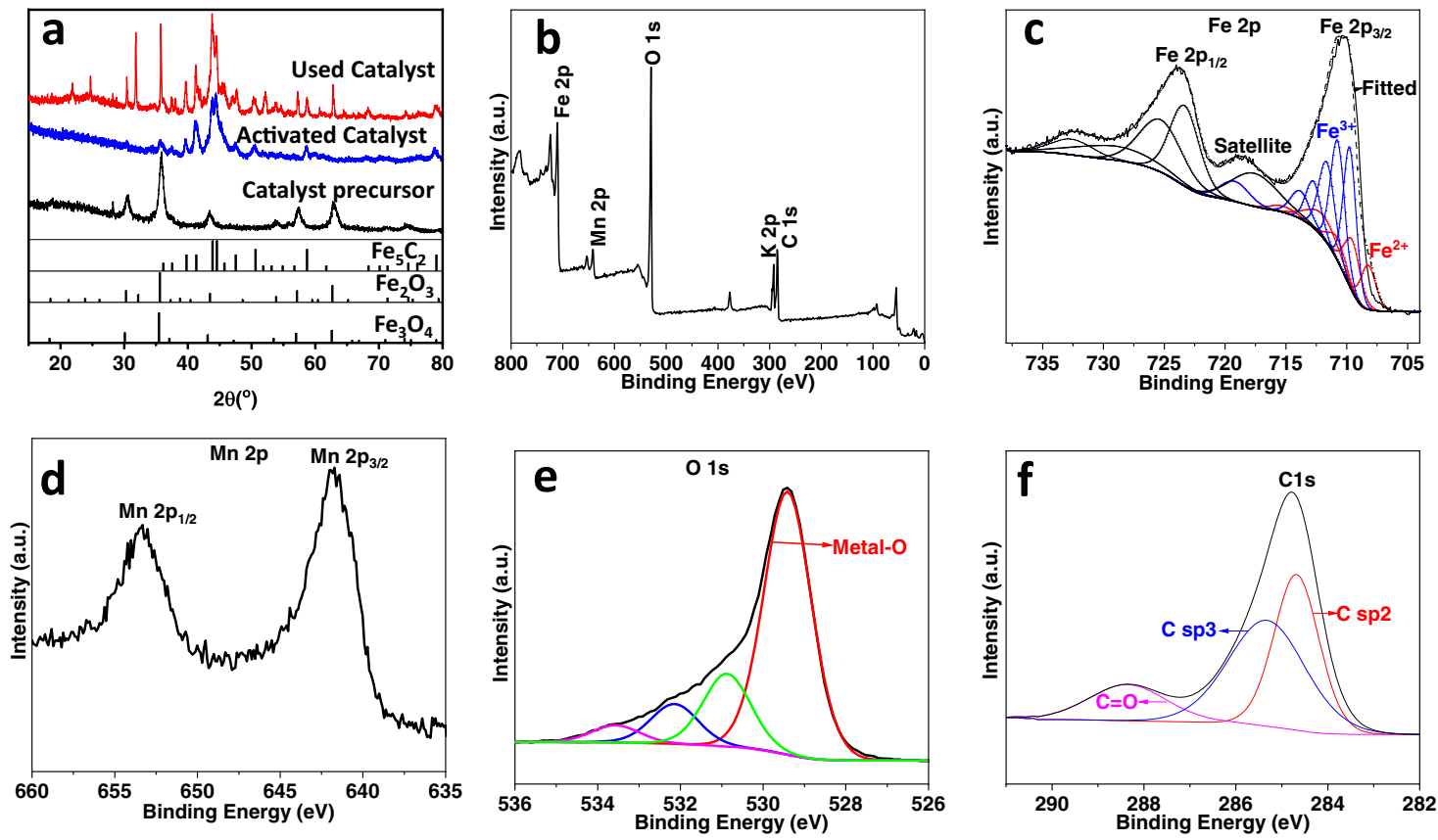

Fig. 2 XRD and XPS spectra of the Fe-Mn-K catalyst. a Powder XRD spectra of the catalyst precursor and both the activated and the used catalyst. The corresponding JCPDS numbers are, for $\mathrm{Fe}_{2} \mathrm{O}_{3}$ : 00-020-0508; $\chi-\mathrm{Fe}_{5} \mathrm{C}_{2}$ : 00-024-0081; $\mathrm{Fe}_{3} \mathrm{O}_{4}$ : 03-065-3107; $\mathbf{b}$ XPS survey spectrum of the Fe-Mn-K catalyst; c High-resolution XPS spectra in the region of the Fe 2p peak on the Fe-Mn-K catalyst; $\mathbf{d}$ XPS spectra of the Mn 2p on the Fe-Mn-K catalyst; e XPS spectra of the $\mathrm{O}$ 1s on the Fe-Mn-K catalyst; $\mathbf{f}$ XPS spectra of the $\mathrm{C}$ 1s on the Fe-Mn-K catalyst.

from $\mathrm{CO}_{2}$ hydrogenation for a reaction time of $20 \mathrm{~h}$, using an example Fe-Mn-K catalyst, is presented in Supplementary Fig. 1.

The data in Fig. 1 illustrate that the $\mathrm{Fe}-\mathrm{Mn}-\mathrm{K}$ catalyst exhibits high activity for the $\mathrm{CO}_{2}$ hydrogenation. The $\mathrm{CO}_{2}$ and $\mathrm{H}_{2}$ conversion increased rapidly with onset of reaction time in the first $5 \mathrm{~h}$, reaching a stable value of around $40 \%$. The methane selectivity decreased from 30 to $10 \%$ from the beginning of the reaction until $20 \mathrm{~h}$, and decreased by a small amount after a further $20 \mathrm{~h}$. In contrast, the light olefin selectivity $\left(\mathrm{C}_{2}-\mathrm{C}_{4}\right.$ olefins) increased to an apparent limiting value of $25 \%$ at a reaction time of $10 \mathrm{~h}$ and above. The liquid product $\left(\mathrm{C}_{5}{ }^{+}\right)$selectivity was stable at around $60 \%$ and showed a small increase with reaction time. Similarly with FTS, the hydrocarbon products from $\mathrm{CO}_{2}$ hydrogenation on $\mathrm{Fe}-\mathrm{Mn}-\mathrm{K}$ generally follow the ASF distribution. Figure $1 \mathrm{~d}$ shows a double ASF product distribution ${ }^{53}$, whose chain growth probabilities $\left(\alpha_{i}\right)$ is 0.79 for $\alpha_{1}$ within the $\mathrm{C}_{1}-\mathrm{C}_{12}$ carbon range and $\alpha_{2}$ is 0.57 for $\mathrm{C}_{12+}$ (i.e., heavy hydrocarbons). A high chain growth probability $\left(\alpha_{1}\right)$ means a low methane selectivity whilst the chain growth decreases when the carbon number is above 12, indicating lower selectivity for higher (heavier) hydrocarbons.

Compared with the literature results in Table 1, the prepared $\mathrm{Fe}-\mathrm{Mn}-\mathrm{K}$ catalyst showed higher liquid products $\left(\mathrm{C}_{5+}\right)$ yield, with the catalyst presenting both high $\mathrm{CO}_{2}$ conversion and high $\mathrm{C}_{5+}$ selectivity.

Interestingly, the methane selectivity decreased dramatically at the beginning of the reaction due to the main reaction being $\mathrm{CO}_{2}$ methanation over the catalyst active sites $\left(\chi-\mathrm{Fe}_{5} \mathrm{C}_{2}\right)$. They produced a high pressure of water and unconverted $\mathrm{CO}_{2}$ which, importantly, can then oxidize $\chi-\mathrm{Fe}_{5} \mathrm{C}_{2}$ to $\mathrm{Fe}_{3} \mathrm{O}_{4}$. The $\mathrm{CO}$ produced via the RWGS reaction on $\mathrm{Fe}_{3} \mathrm{O}_{4}$ active site reacts with $\mathrm{H}_{2}$ (Fisher-Tropsch synthesis (FTS)), and the $\mathrm{CO}_{2}$ conversion increased rapidly (Fig. 1a). The product selectivity was then stable after a reaction time of $10 \mathrm{~h}$.

The catalyst also showed a high selectivity for the production of light olefins versus alkanes, with molar ratios of ethylene -to -ethane, propylene-to-propane, and butane-to-butane of 5, 8.5, and 7 , respectively (Fig. 1c). The GC-FID chromatograms (Supplementary Fig. 1) also show that olefins were the dominant products in the $\mathrm{C}_{2}-\mathrm{C}_{4}$ hydrocarbon fractions. Overall, the $\mathrm{Fe}-\mathrm{Mn}-\mathrm{K}$ catalyst showed high activity for $\mathrm{CO}_{2}$ hydrogenation reactions and high liquid hydrocarbon, and light olefin product selectivity.

The GC-MS spectrum of the collected liquid products clearly demonstrates that the $\mathrm{Fe}-\mathrm{Mn}-\mathrm{K}$ catalyst has high selectivity for jet fuel range hydrocarbons as liquid products; the total jet fuel range hydrocarbon selectivity is up to $47.8 \%$ among all hydrocarbons. The corresponding yield of jet fuel range hydrocarbons was $17.2 \%$ with a $\mathrm{CO}_{2}$ conversion of $38.2 \%$.

Catalyst characterisation. The catalyst precursor was firstly activated in situ with syngas $\left(\mathrm{H}_{2}: \mathrm{CO}=2: 1\right)$ prior to catalytic performance evaluation, with a GHSV (gas hourly space velocity) conditions of $1000 \mathrm{~mL} \mathrm{~g}^{-1} \mathrm{~h}^{-1}$ at atmospheric pressure, a temperature of $320^{\circ} \mathrm{C}$ and for $24 \mathrm{~h}$ duration. The powder X-ray diffraction (XRD) spectra of the catalyst precursor, together with the activated and used $\mathrm{Fe}-\mathrm{Mn}-\mathrm{K}$ catalysts are shown in Fig. 2 (a).

It can be seen from Fig. $2 \mathrm{a}$, that all the reflections from the catalyst precursor can be assigned to $\mathrm{Fe}_{3} \mathrm{O}_{4}$ but in contrast, and importantly, all reflections from the activated catalyst can be assigned to $\chi-\mathrm{Fe}_{5} \mathrm{C}_{2}$, which indicated that the $\mathrm{Fe}_{3} \mathrm{O}_{4}$ is fully carburized to $\chi-\mathrm{Fe}_{5} \mathrm{C}_{2}$ under the treatment with syngas $\left(\mathrm{CO} / \mathrm{H}_{2}\right.$ ratio of 1:2). The reflections in the powder diffractogram from the used catalyst phase were considerably more complex, consisting of mixtures of $\mathrm{Fe}_{3} \mathrm{O}_{4}, \mathrm{Fe}_{2} \mathrm{O}_{3}$, and $\chi-\mathrm{Fe}_{5} \mathrm{C}_{2}$. Importantly, $\chi-\mathrm{Fe}_{5} \mathrm{C}_{2}$ is widely acknowledged to be the active catalytic species in the in situ hydrogenation of $\mathrm{CO}$ and/or $\mathrm{CO}_{2}$ and this iron carbide phase plays a crucial role in the subsequent $\mathrm{C}-\mathrm{C}$ chain growth reactions ${ }^{54-57}$.

We have observed that the catalyst precursor is almost fully converted to $\chi-\mathrm{Fe}_{5} \mathrm{C}_{2}$ during the in situ activation process, whilst $\mathrm{Fe}_{3} \mathrm{O}_{4}$ is partially regenerated during the first hours of the 


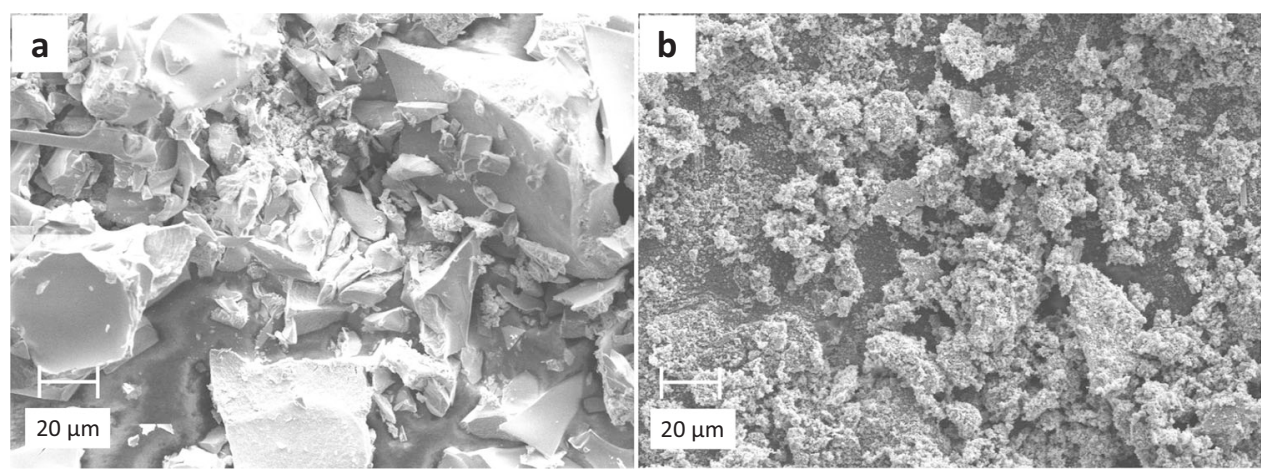

Fig. 3 SEM images of Fe-Mn-K catalyst. a The Fe-Mn-K catalyst precursor; $\mathbf{b}$ the used Fe-Mn-K catalyst.

\begin{tabular}{|c|c|c|c|c|}
\hline Catalyst & $2 \theta$ & FWHM & d-spacing (nm) & Crystallite size (nm) \\
\hline $\mathrm{Fe}-\mathrm{Zn}-\mathrm{K}$ & 35.73 & 0.13 & 0.25 & 64 \\
\hline $\mathrm{Fe}-\mathrm{Cu}-\mathrm{K}$ & 35.91 & 0.11 & 0.25 & 74 \\
\hline Fe-Mn-K & 35.75 & 0.60 & 0.25 & 14 \\
\hline
\end{tabular}

catalytic reaction, hence explaining the increases in $\mathrm{H}_{2}$ and $\mathrm{CO}_{2}$ conversion during this period. This finding is perfectly consistent with the recognized "Tandem mechanism" in which these two catalytically active phases $\left(\chi-\mathrm{Fe}_{5} \mathrm{C}_{2}\right.$ and $\left.\mathrm{Fe}_{3} \mathrm{O}_{4}\right)$ are responsible for the conversion of $\mathrm{CO}_{2}$ and $\mathrm{H}_{2}$ to syngas and for the subsequent $\mathrm{C}-\mathrm{C}$ chain growth step to produce jet fuel ${ }^{44,58-60}$.

The formation of $\mathrm{Fe}_{2} \mathrm{O}_{3}$ in the used catalyst probably arises from the oxidation of $\mathrm{Fe}_{3} \mathrm{O}_{4}$ by $\mathrm{CO}_{2}$ and/or water during the reaction, while the $\mathrm{Fe}_{2} \mathrm{O}_{3}$ was reduced to $\mathrm{Fe}_{3} \mathrm{O}_{4}$ in the presence of $\mathrm{H}_{2}$ (showed in Supplementary Fig. 24).

Crystallite sizes were calculated using the Scherrer equation for the Fe-based catalysts precursor and these are listed in Table 2 . The crystallite size for the $\mathrm{Fe}-\mathrm{Mn}-\mathrm{K}$ catalyst is typically around $14 \mathrm{~nm}$, which is reflected in the observed broad reflections in the XRD spectrum of the catalyst precursor (as shown in Fig. 2).

Surface elemental compositions and the oxidation states of the metals were analyzed using XPS in the region $0-800 \mathrm{eV}$. The survey spectrum (Fig. 2b) clearly indicates that the sample contains $\mathrm{Fe}, \mathrm{Mn}, \mathrm{K}$, and $\mathrm{O}$. Figure 2c shows the XPS spectrum of the Fe $2 p$ region, which can be fitted with two spin-orbit doublets corresponding to the $\mathrm{Fe} 2 \mathrm{p}_{3 / 2}$ and $\mathrm{Fe} 2 \mathrm{p}_{1 / 2}$ peaks with a binding energy gap of $13.7 \mathrm{eV}$ and a shakeup satellite which is assigned to $\mathrm{Fe}^{3+}$, consistent with those for $\mathrm{Fe}_{3} \mathrm{O}_{4}{ }^{61}$. The measured molar ratio of $\mathrm{Fe}^{2+}: \mathrm{Fe}^{3+}$ is 1:2.38, which approximates to the stoichiometry of $\mathrm{Fe}_{3} \mathrm{O}_{4}$ (the ratio of $\mathrm{Fe}^{2+}: \mathrm{Fe}^{3+}$ for $\mathrm{Fe}_{3} \mathrm{O}_{4}$ is 1:2). In Fig. $2 d$ we show the Mn $2 p$ XPS spectra, which displayed a spin-orbit doublet of $\mathrm{Mn} \mathrm{2p3/2}$ and $\mathrm{Mn} 2 \mathrm{p} 1 / 2$ peaks with a binding energy gap of $11.6 \mathrm{eV}$ can be assigned to $\mathrm{Mn}_{2} \mathrm{O}_{3}$. In addition, in Fig. 2e we show the O 1s, XPS spectra with a main peak at $529.4 \mathrm{eV}$, clearly originating from the presence of metalO bonds.

The XPS spectra of the $\mathrm{C} 1 \mathrm{~s}$ present (Fig. 2f) showed that around $40 \%$ of $\mathrm{C} \mathrm{sp} 2$ at a characteristic binding energy peak of $284.7 \mathrm{eV}$; some $15 \% \mathrm{C}=\mathrm{O}$ at a binding energy peak of $288.4 \mathrm{eV}$; and finally, $45 \% \mathrm{C}$ sp3 at binding energy peak of $285.3 \mathrm{eV}$. The C sp2 is due to the carbon residue due to the calcination of citric acid, and the peak of $\mathrm{C}=\mathrm{O}$ and $\mathrm{C} s p 3$ can be attributed to the citric acid residues which have not fully decomposed.
Temperature-programmed oxidation (TPO) results of Fe-Mn-K catalyst precursor prepared with citric acid combustion method shown in Supplementary Fig. 24 revealed a small amount (about 3.5 wt\%) of carbon residue in the after calcination at $350{ }^{\circ} \mathrm{C}$. The presence of this small amount of carbon in the catalyst is reported to be beneficial for a higher olefin product selectivity. Thus, previous work ${ }^{62,63}$ reported that the surrounding carbonaceous matter could indeed facilitate the formation of iron carbides during activation, hence improving the higher liquid products selectivity.

Scanning electron microscopy (SEM) images of both the catalyst precursor and the used catalysts are shown in Fig. 3. The precursor consists of closely packed, regular particles (Fig. 3a). Obvious changes take place in the morphology of the catalyst after reaction (Fig. 3b). STEM-BF images of the catalyst precursor and used catalyst were also recorded as shown in Fig. 4.

From Fig. $4 \mathrm{a}-\mathrm{c}$ it is evident that the catalyst precursor consists of nanoparticles with sizes of $\sim 15 \mathrm{~nm}$. Interestingly, there was no obvious change in catalyst particle size following the hydrogenation reaction (Fig. 4d). In the catalyst precursor (Fig. 4b, c), the measured lattice spacings of 0.25 and $0.3 \mathrm{~nm}$ correspond to the (311) and (220) planes of $\mathrm{Fe}_{3} \mathrm{O}_{4}$, respectively. In addition to the $\mathrm{Fe}_{3} \mathrm{O}_{4}$ phase (Fig. 4e), a $\chi-\mathrm{Fe}_{5} \mathrm{C}_{2}$ phase was also observed in the used catalysts (Fig. 4f). This has been proposed as the source of the catalytically active sites for $\mathrm{CO}$ and/or $\mathrm{CO}_{2}$ hydrogenation to hydrocarbons, as previously reported ${ }^{54-57}$.

The effects of transition metal promoters. Manganese compounds are widely utilised as promoters in iron-based catalysts for FTS where the addition of Mn typically improves activity, increases the surface basicity and enhances the carburization of the catalyst ${ }^{64,65}$. In addition to $\mathrm{Mn}, \mathrm{Zn}^{66,67}$ and $\mathrm{Cu}^{43,68}$ have also been used as promoters for Fe-based catalysts for FTS. Thus, $\mathrm{Fe}-\mathrm{Zn}-\mathrm{K}$ and $\mathrm{Fe}-\mathrm{Cu}-\mathrm{K}$ catalysts were also prepared by the same method as the $\mathrm{Fe}-\mathrm{Mn}-\mathrm{K}$ catalyst. The catalytic performance for $\mathrm{CO}_{2}$ hydrogenation using these different catalysts are shown in Fig. 1e, $f$.

The data in Fig. 1e show that even the iron-catalyst without promoter showed high activity for $\mathrm{CO}_{2}$ hydrogenation, as reflected in the high conversion values. However, from Fig. If we can see the methane selectivity was very high, and reached $32.2 \%$ while the liquid product selectivity was very low.

In contrast, the promoter-added catalysts, $\mathrm{Fe}-\mathrm{Zn}-\mathrm{K}, \mathrm{Fe}-\mathrm{Cu}-\mathrm{K}$, and $\mathrm{Fe}-\mathrm{Mn}-\mathrm{K}$ showed high $\mathrm{CO}_{2}$ conversion and high jet fuel range hydrocarbon selectivity. There was no significant difference between the performances of these three catalysts, but the $\mathrm{Fe}-\mathrm{Mn}-\mathrm{K}$ catalyst showed slightly better selectivity for jet fuels synthesis (47.8\%) than catalysts of $\mathrm{Fe}-\mathrm{Cu}-\mathrm{K}(40.8 \%)$ and $\mathrm{Fe}-\mathrm{Zn}-\mathrm{K}(45.1 \%)$. 


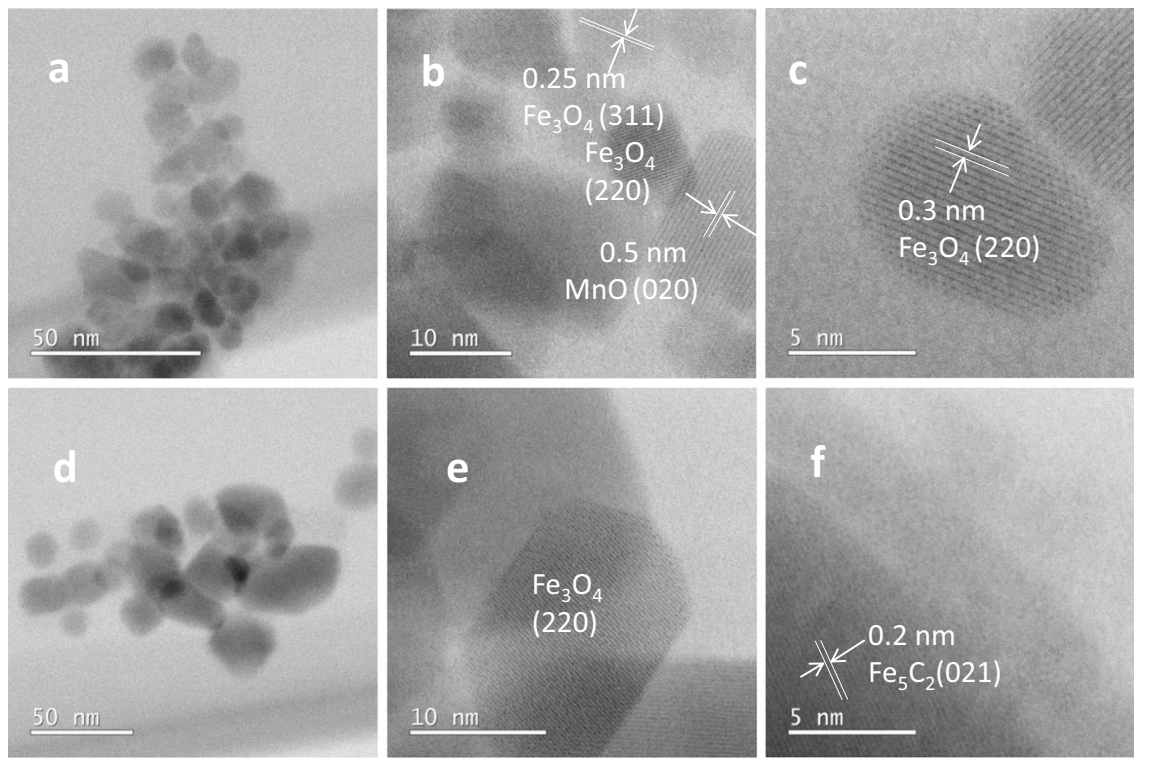

Fig. 4 STEM-BF images of the Fe-Mn-K at different nanoscales. a-c The Fe-Mn-K catalyst precursor; $\mathbf{d}-\mathbf{f}$ the used Fe-Mn-K catalyst.

\section{Table 3 Crystallite size of the various prepared catalysts} (different base metal) with citric acid method.

\begin{tabular}{|lllll} 
Catalyst & $\mathbf{2 \theta}$ & FWHM & d-spacing (nm) & Crystallite size (nm) \\
\hline Fe-Mn-Li & 36.07 & 0.45 & 0.25 & 19 \\
Fe-Mn-Na & 35.98 & 0.26 & 0.25 & 32 \\
Fe-Mn-Cs & 36.03 & 0.30 & 0.25 & 28 \\
\hline
\end{tabular}

Effects of base-metal promoters. The impact of potassium (K) compounds on the performance of Fe-based catalysts for FTS has been studied extensively $69,70 . \mathrm{K}$ is known to promote the formation of longer-chain hydrocarbons, the carburization of surface $\mathrm{Fe}$, and the suppression of $\mathrm{CH}_{4}$ formation, all of which are advantageous for liquid hydrocarbon synthesis. In addition to $\mathrm{K}$, various base metal compounds of $\mathrm{Na}$ have also been used as promoters for FTS catalysts ${ }^{71,72}$. Therefore, these base metals have also been tested as promoters for the catalytic hydrogenation of $\mathrm{CO}_{2}$ and their various catalytic performance are summarised in Fig. 1e, $f$.

It is clear from the data in Fig. 1e, that $\mathrm{Na}, \mathrm{K}$, and Cs-based promoters all show both high activity for $\mathrm{CO}_{2}$ hydrogenation and high selectivity for hydrocarbons in the jet fuel range. However, the Li promoted catalyst showed high selectivity for methane formation but not for long-chain hydrocarbons (Fig. 1f). There are no large differences in the catalytic performance between the catalysts $\mathrm{Fe}-\mathrm{Mn}-\mathrm{K}, \mathrm{Fe}-\mathrm{Mn}-\mathrm{Na}$, and $\mathrm{Fe}-\mathrm{Mn}-\mathrm{Cs}$. However, the $\mathrm{Fe}-\mathrm{Mn}-\mathrm{K}$ catalyst showed higher $\mathrm{C}_{8}-\mathrm{C}_{16}$ selectivity (47.8\%) than $\mathrm{Fe}-\mathrm{Mn}-\mathrm{Na}(44.4 \%)$ or $\mathrm{Fe}-\mathrm{Mn}-\mathrm{Cs}(44.0 \%)$.

Crystallite sizes calculated using the Scherrer equation for the different base metal promoted catalysts precursor are listed in Table 3 . The catalysts have different crystallite sizes ranging from 19 to $32 \mathrm{~nm}$.

Effects of organic fuel compounds. Recently, the OrganicCombustion Method (OCM), also known as the Solution Combustion Method, has been developed to prepare highly active metal catalysts for a variety of processes ${ }^{73}$. In order to investigate the fundamental, underlying efforts of organic fuel compounds, the catalyst prepared without fuel also been synthesised. It is clear that the catalyst prepared without fuel showed lower catalytic activity $\left(\mathrm{CO}_{2}\right.$ conversion of 28.6\%) compared with the catalyst prepared with citric acid $\left(\mathrm{CO}_{2}\right.$ conversion of 38.2\%). In addition to using citric acid as a fuel in the OCM catalyst preparation, we have also investigated other organic chemicals as potential fuel sources. A series of catalysts of the $\mathrm{Fe}-\mathrm{Mn}-\mathrm{K}$ type were therefore prepared with different organic compounds in the catalyst preparation by the combustion route and their catalytic performances for the hydrogenation of $\mathrm{CO}_{2}$ are listed in Table 4 .

It is clear, therefore, that compared to the catalyst prepared without an organic fuel, all the $\mathrm{Fe}-\mathrm{Mn}-\mathrm{K}$ catalysts prepared with organic compounds generally showed both higher $\mathrm{CO}_{2}$ conversion and higher jet fuel range hydrocarbon selectivity. The catalysts prepared with EDTA, citric acid, oxalic acid, NTA, DTPA, Tartaric acid, HEDTA, and salicylic acid also exhibited good catalytic performance for both $\mathrm{CO}_{2}$ conversion and jet fuel selectivity. In general, all these organic fuels could also act as chelating agents and hence facilitating the formation of nanostructured catalysts.

The XRD spectra of various catalysts are shown in Supplementary Fig. 4. The catalyst prepared without fuel showed characteristic reflections assigned to $\mathrm{Fe}_{2} \mathrm{O}_{3}$. However, most of the catalysts prepared with organic fuel compounds showed $\mathrm{Fe}_{3} \mathrm{O}_{4}$ as the dominant crystalline phase which clearly indicates that part of $\mathrm{Fe}^{3+}$ present in $\mathrm{Fe}_{2} \mathrm{O}_{3}$ was partially reduced to $\mathrm{Fe}^{2+}$ in $\mathrm{Fe}_{3} \mathrm{O}_{4}$ during the catalyst preparation stage. The catalyst prepared with oxalic acid showed XRD reflections corresponding to $\mathrm{Fe}_{2} \mathrm{O}_{3}$ instead of $\mathrm{Fe}_{3} \mathrm{O}_{4}$. This implies that under the conditions applied in this investigation, oxalic acid did not reduce the $\mathrm{Fe}_{2} \mathrm{O}_{3}$ to $\mathrm{Fe}_{3} \mathrm{O}_{4}$ consistent with its low reducing power compared to the other organic fuels.

The crystallite sizes of catalysts calculated from the Scherrer equation are listed in Table 5. Importantly, catalysts prepared with a range of different organic compounds showed smaller crystallite sizes than the catalyst prepared without fuel. We attribute these differences in crystallite sizes as the possible origins of the higher activity of catalysts prepared with organic fuels.

Compared to the co-precipitation method, widely applied in the preparation of Fe-based catalysts ${ }^{49-52}$, we show that the OCM is a particularly facile production process where, in addition to 
Table 4 Effect of organic (fuel) compounds on $\mathrm{CO}_{2}$ hydrogenation catalyst performance. All reactions were conducted at $1 \mathrm{MPa}$, $300{ }^{\circ} \mathrm{C}$, GHSV $2400 \mathrm{ml} \mathrm{g}^{-1} \mathrm{~h}^{-1}$ and $\mathrm{H}_{2}: \mathrm{CO}_{2}$ (3:1) on Fe-Mn-K catalyst.

\begin{tabular}{|c|c|c|c|c|c|c|c|c|}
\hline \multirow{2}{*}{$\begin{array}{l}\text { Organic compound applied in catalysts } \\
\text { preparation }\end{array}$} & \multicolumn{2}{|c|}{ Conversion (\%) } & \multirow[t]{2}{*}{ CO selectivity (\%) } & \multicolumn{5}{|c|}{ Selectivity to hydrocarbons (\%) } \\
\hline & $\mathbf{H}_{2}$ & $\mathrm{CO}_{2}$ & & $\mathrm{CH}_{4}$ & $\mathbf{C}_{2-4}=$ & $\mathrm{C}_{2-4} \mathrm{O}$ & $\mathbf{C}_{5+}$ & $C_{8-16}$ \\
\hline No fuel & 27.0 & 28.6 & 6.5 & 14.1 & 26.0 & 5.2 & 54.7 & - \\
\hline Urea & 34.4 & 35.0 & 5.8 & 14.3 & 27.6 & 4.6 & 53.5 & 38.3 \\
\hline Tannic acid & 39.2 & 38.8 & 5.0 & 16.2 & 26.4 & 4.8 & 52.6 & 34.5 \\
\hline EDTA & 39.6 & 40.6 & 7.0 & 13.5 & 21.6 & 4.4 & 60.5 & 51.0 \\
\hline Citric acid & 39.5 & 38.2 & 5.6 & 10.4 & 24.2 & 3.5 & 61.9 & 47.8 \\
\hline Oxalic acid & 36.7 & 37.0 & 7.4 & 9.8 & 25.4 & 3.5 & 61.3 & 47.9 \\
\hline NTA & 39.5 & 42.5 & 5.1 & 7.2 & 18.3 & 2.6 & 71.9 & 49.0 \\
\hline DTPA & 42.0 & 44.0 & 6.2 & 9.6 & 19.0 & 3.4 & 68.0 & 53.3 \\
\hline Tartaric acid & 40.1 & 41.8 & 4.6 & 7.9 & 18.9 & 2.7 & 70.4 & 50.2 \\
\hline HEDTA & 42.3 & 41.5 & 4.9 & 9.6 & 20.2 & 3.1 & 67.0 & 47.0 \\
\hline Salicylic acid & 37.8 & 37.3 & 7.2 & 12.6 & 22.0 & 3.8 & 61.5 & 49.5 \\
\hline Sugar & 36.5 & 37.4 & 8.8 & 10.3 & 21.5 & 3.9 & 64.3 & 45.8 \\
\hline Flour powder & 36.5 & 35.6 & 7.2 & 12.1 & 25.9 & 4.0 & 58.0 & 39.8 \\
\hline
\end{tabular}

\begin{tabular}{lllll|}
$\begin{array}{l}\text { Table } 5 \text { Crystallite size of catalysts prepared with different } \\
\text { organic compounds. }\end{array}$ & & & \\
$\begin{array}{l}\text { Organic compound } \\
\text { applied in } \\
\text { catalysts } \\
\text { preparation }\end{array}$ & $\mathbf{2 \theta}$ & FWHM & $\begin{array}{l}\text { d-spacing } \\
\text { (nm) }\end{array}$ & $\begin{array}{l}\text { Crystallite } \\
\text { size (nm) }\end{array}$ \\
\hline- & & & & \\
Urea & 33.42 & 0.13 & 0.27 & 63 \\
Tannic acid & 35.83 & 0.15 & 0.25 & 56 \\
EDTA & 35.85 & 0.60 & 0.25 & 14 \\
Glycine & 35.74 & 0.67 & 0.25 & 12 \\
Citric acid & 35.46 & 0.30 & 0.25 & 28 \\
Oxalic acid & 35.75 & 0.60 & 0.25 & 14 \\
NTA & 35.87 & 0.45 & 0.25 & 19 \\
DTPA & 35.94 & 0.34 & 0.25 & 25 \\
Tartaric acid & 35.96 & 0.67 & 0.25 & 12 \\
HEDTA & 35.78 & 0.30 & 0.25 & 28 \\
Salicylic acid & 35.95 & 0.37 & 0.25 & 22 \\
Sugar & 35.69 & 1.20 & 0.25 & 7 \\
Flour powder & 36.04 & 0.11 & 0.25 & 74 \\
\hline
\end{tabular}

high yields and selectivity for jet fuels, additional advantages are savings in both energy and time ${ }^{74}$.

An optimal organic compound in our catalyst preparation should act both as a reducing agent and should react with nitrates non-violently, produce nontoxic gases and also act as an effective chelating agent for metal cations.

The catalysts prepared using organic fuels showed high activity as stable organic chelate compounds formed with metal cations are particularly suited to the formation of uniform, highly dispersed metal oxide catalysts via the combustion method.

The gaseous products from the organic compound and nitrate combustion reactions are $\mathrm{N}_{2}, \mathrm{CO}_{2}$, and $\mathrm{H}_{2} \mathrm{O}$. Using citric acid as an example, the stoichiometric reactions can be described as follows, according to the principle of propellant chemistry:

$$
\begin{array}{r}
54 \mathrm{Fe}\left(\mathrm{NO}_{3}\right)_{3} 9 \mathrm{H}_{2} \mathrm{O}+46 \mathrm{C}_{6} \mathrm{H}_{8} \mathrm{O}_{7} \mathrm{H}_{2} \mathrm{O} \\
\rightarrow 18 \mathrm{Fe}_{3} \mathrm{O}_{4}+81 \mathrm{~N}_{2}+276 \mathrm{CO}_{2}+716 \mathrm{H}_{2} \mathrm{O}
\end{array}
$$

$$
\begin{array}{r}
\quad 9 \mathrm{Mn}\left(\mathrm{NO}_{3}\right)_{2} 4 \mathrm{H}_{2} \mathrm{O}+5 \mathrm{C}_{6} \mathrm{H}_{8} \mathrm{O}_{7} \mathrm{H}_{2} \mathrm{O} \\
\rightarrow 9 \mathrm{MnO}+9 \mathrm{~N}_{2}+30 \mathrm{CO}_{2}+61 \mathrm{H}_{2} \mathrm{O}
\end{array}
$$

These combustion reactions are highly exothermic and lead to a rapid evolution of a large volume of gaseous products during the catalysts preparation process. This release of gas depletes the fuel combustion heat and hence limits the rapid temperature rise, thereby advantageously reducing any premature local partial sintering of the primary metals oxides particles. The gas evolution also results in limiting any extended crystal growth or inter particle contact, thereby contributing to smaller particle size catalysts ${ }^{75}$.

Although combustion was nominally carried out at $350^{\circ} \mathrm{C}$, the in situ flame temperature during combustion can be very high due to the combustion of gases produced during the decomposition of metal nitrates and the organic compounds. This hightemperature persists for a few minutes and disappears, producing a rapid quenching effect $^{76}$. which is known to enhance the interaction between $\mathrm{Fe}_{3} \mathrm{O}_{4}$ and the promoter, further improving catalytic performance. It is interesting that most of redox gel when combusted at a calcining temperature of $350^{\circ} \mathrm{C}$, produces $\mathrm{Fe}_{3} \mathrm{O}_{4}$ without any apparent $\mathrm{O}_{2}$ participation from the atmosphere However, the main products are $\mathrm{Fe}_{2} \mathrm{O}_{3}$ when the calcination temperature increased to $500^{\circ} \mathrm{C}$, one presumes clearly as a consequence of the participation of atmospheric oxygen and/ or the associated oxygens from the complexing ligands.

In general, the $\mathrm{Fe}-\mathrm{Mn}-\mathrm{K}$ catalysts synthesised with carboxylic acids and polycarboxylic acids as fuels showed superior catalytic performances than those prepared using urea and sugar (glucose) and the catalyst prepared without fuel. Our assertion is that this trend probably derives from two crucial roles (i.e., both a chelating agent and fuel) that these organic molecules play in the organic-combustion approach. The first role can enhance the homogeneity of the solution through the intimacy between the constituent metal $(\mathrm{Fe}, \mathrm{Mn}, \mathrm{K})$ precursors, hence hindering their precipitation or aggregation during the gel formation, whilst the second (fuel) function can closely control the severity of the combustion reaction and hence the aggregation of the nanostructured catalysts. Obviously, this leads to changes in the crystallite sizes that show the $\mathrm{Fe}-\mathrm{Mn}-\mathrm{K}$ catalysts with particle sizes between 7 and $28 \mathrm{~nm}$ and usually prepared by carboxylic acid-type fuels are significantly more active and selective than the catalysts with larger crystallite sizes (i.e., 56-74 nm). 


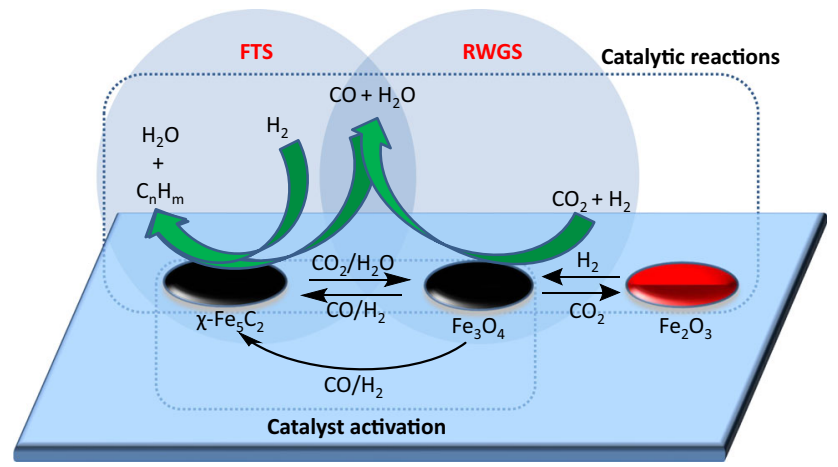

Fig. 5 Reaction scheme for $\mathrm{CO}_{2}$ hydrogenation to jet fuel range hydrocarbons. The $\mathrm{CO}_{2}$ hydrogenation to jet fuel range hydrocarbons process through a Tandem Mechanism in which the Reverse-Water Gas Shift reaction (RWGS) and Fischer-Tropsch synthesis (FTS) reaction are catalysed by $\mathrm{Fe}_{3} \mathrm{O}_{4}$ and $\chi-\mathrm{Fe}_{5} \mathrm{C}_{2}$ respectively.

Finally, we have also examined commercial sugar and flour powders as possible fuels in the catalyst preparation process. Catalysts prepared with these fuels also showed high $\mathrm{CO}_{2}$ hydrogenation activity and jet fuel range hydrocarbon selectivity. The catalytic performance for $\mathrm{CO}_{2}$ hydrogenation of catalysts prepared with different fuels are shown in Supplementary Figs. 10-22.

The reaction scheme. Hägg carbide $\left(\chi-\mathrm{Fe}_{5} \mathrm{C}_{2}\right)$ is widely accepted to be the active catalytic species in the FTS and this iron carbide phase plays a crucial role in the $\mathrm{C}-\mathrm{C}$ chain growth reactions ${ }^{54-57}$. The $\chi-\mathrm{Fe}_{5} \mathrm{C}_{2}$ usually prepared by activation of hematite under syngas atmosphere at temperature of $200-450{ }^{\circ} \mathrm{C}$, the whole activation process contains a three-step reduction process of $\mathrm{Fe}_{2} \mathrm{O}_{3}$ to iron $\left(\mathrm{Fe}_{2} \mathrm{O}_{3} \rightarrow \mathrm{Fe}_{3} \mathrm{O}_{4} \rightarrow \mathrm{FeO} \rightarrow \mathrm{Fe}\right)$ and then followed by carburisation of $\mathrm{Fe}$ to $\chi-\mathrm{Fe}_{5} \mathrm{C}_{2}{ }^{77}$. In our experiments, the $\chi$ $\mathrm{Fe}_{5} \mathrm{C}_{2}$ was reduced and carburized from $\mathrm{Fe}_{3} \mathrm{O}_{4}$, in the process of magnetite $\left(\mathrm{Fe}_{3} \mathrm{O}_{4}\right) \rightarrow$ wüstite $(\mathrm{FeO}) \rightarrow$ iron metal $(\mathrm{Fe}) \rightarrow$ Hägg carbide $\left(\chi-\mathrm{Fe}_{5} \mathrm{C}_{2}\right)$. Wei et al. ${ }^{44}$ have proposed a comprehensive reaction scheme where $\chi \mathrm{Fe}_{5} \mathrm{C}_{2}$ is involved in the hydrogenation of $\mathrm{CO}_{2}$ to gasoline fuel range hydrocarbons, using a $\mathrm{Na}-\mathrm{Fe}_{3} \mathrm{O}_{4} /$ Zeolite multifunctional catalyst. We believe that a related, but slightly different, reaction scheme is operating here for the hydrogenation of $\mathrm{CO}_{2}$ to aviation jet fuel and this is illustrated schematically in Fig. 5.

In contrast to the report by Wei et al. ${ }^{44}$ who described catalysts prepared by a one-pot synthesised $\mathrm{Na}-\mathrm{Fe}_{3} \mathrm{O}_{4}$ catalyst with zeolite, we have prepared catalysts using the direct OCM route which showed higher liquid products yield on $\mathrm{CO}_{2}$ hydrogenation. Thus the $\mathrm{Fe}_{3} \mathrm{O}_{4}$ catalyst precursor is fully carburized to $\chi-\mathrm{Fe}_{5} \mathrm{C}_{2}$ during our catalyst activation (reduction) process, whilst $\mathrm{Fe}_{3} \mathrm{O}_{4}$ is partially regenerated from the oxidation of $\chi-\mathrm{Fe}_{5} \mathrm{C}_{2}$ by $\mathrm{CO}_{2}$ /water in the first hours of the catalytic reaction. Jet fuel synthesis via $\mathrm{CO}_{2}$ hydrogenation initially takes place by the RWGS reaction $\left(\mathrm{CO}_{2}+\mathrm{H}_{2} \rightarrow \mathrm{CO}+\mathrm{H}_{2}\right)$ on the catalytically active sites of $\mathrm{Fe}_{3} \mathrm{O}_{4}$, and subsequently by the FTS reactions $\left(\mathrm{CO}+\mathrm{H}_{2} \rightarrow \mathrm{C}_{\mathrm{n}} \mathrm{H}_{\mathrm{m}}+\right.$ $\left.\mathrm{H}_{2} \mathrm{O}\right)$ on catalytically active sites on $\chi-\mathrm{Fe}_{5} \mathrm{C}_{2}{ }^{54-57}$.

Using iron-based catalysts for FT synthesis a fast and reversible exchange of $\mathrm{Fe}_{3} \mathrm{O}_{4}$ to $\mathrm{Fe}_{x} \mathrm{C}_{y}$ carbides and vice versa can occur under appropriate reaction conditions. This relatively facile and reversible phase transformation makes possible the incorporation of carbon atoms from the carbide surface into the reaction products via Mars-van Krevelen mechanism as was determined by Gracia et al. ${ }^{78}$ through a computational study of the CO hydrogenation on an iron carbide surface. Remarkably, this Mars- van Krevelen-like mechanism on supported Fe catalysts rationalised the enhanced reactivity of highly dispersed iron carbide particles in the initiation of chain growth in F-T synthesis ${ }^{79}$.

As far as we know, there is not a single report in the scientific literature of the Mars-van Krevelen mechanism operating in the $\mathrm{CO}_{2}$ hydrogenation reaction on $\mathrm{Fe}$ catalysts. Obviously, this reaction is more challenging than conventional FT synthesis since the catalyst must have an excellent balance of active sites (phases) to catalyse-in tandem mode-the reverse-water gas shift reaction (or $\mathrm{CO}_{2}$ partial hydrogenation) and also the $\mathrm{CO}$ hydrogenation via the FT reaction to produce Jet Fuel. Our tandem mechanism through the participation of $\mathrm{Fe}_{3} \mathrm{O}_{4}$ and $\chi-$ $\mathrm{Fe}_{5} \mathrm{C}_{2}$ can easily rationalise the jet fuel formation and give a wider picture of the evolution of the gas, liquid and solid phases during the catalytic reaction. Further work is needed to gain further insight into the possible occurrence of Mars-van Krevelen-like mechanism in the FT stage through carbon isotopic labelling studies. In a flowing gas system these will clearly be experimentally-and financially (!)-challenging.

The carbide phase detected by powder-XRD diffraction was $\chi$ $\mathrm{Fe}_{5} \mathrm{C}_{2}$ which plays a principal role in the formation of hydrocarbons via FT reaction ${ }^{54-57}$. According to the literature and our own results, the carburization process of Fe nanoparticles during the catalytic reaction forms the Fe carbide phase, which through a FT pathway favours the $\mathrm{C}-\mathrm{C}$ condensation reactions to produce large hydrocarbons within the range of aviation fuel. In our experiments, the $\chi-\mathrm{Fe}_{5} \mathrm{C}_{2}$ was formed during the catalyst activation/reduction process, in the beginning of the reaction what it is happening is mainly $\mathrm{CO}_{2}$ methanation reaction on $\chi^{-}$ $\mathrm{Fe}_{5} \mathrm{C}_{2}$, the relatively high pressure of water can then oxidize on $\chi-$ $\mathrm{Fe}_{5} \mathrm{C}_{2}$ to $\mathrm{Fe}_{3} \mathrm{O}_{4}$, and the $\mathrm{Fe}_{3} \mathrm{O}_{4}$ was simultaneously carburized by $\mathrm{CO}^{80}$. In model experiments, $\mathrm{Fe}_{2} \mathrm{O}_{3}$ was produced from the oxidation of $\mathrm{Fe}_{3} \mathrm{O}_{4}$ by $\mathrm{CO}_{2} / \mathrm{H}_{2} \mathrm{O}$, and $\mathrm{Fe}_{2} \mathrm{O}_{3}$ was steadily reduced to $\mathrm{Fe}_{3} \mathrm{O}_{4}$ by $\mathrm{H}_{2}$ in the reaction system (Supplementary Fig. 23). Thus $\mathrm{Fe}_{3} \mathrm{O}_{4}, \chi-\mathrm{Fe}_{5} \mathrm{C}_{2}$, and $\mathrm{Fe}_{2} \mathrm{O}_{3}$ co-exist during the reaction. Using Mn compounds as a promoter noticeably improved the catalyst FTS activity, increased the catalyst surface basicity and enhanced the carburization of the catalyst ${ }^{64,65}$. The addition of $\mathrm{K}$ compounds promoted the formation of longer-chain hydrocarbon molecules, the carburization of surface $\mathrm{Fe}$, and the suppression of $\mathrm{CH}_{4}$ formation, which strongly favours liquid hydrocarbon synthesis ${ }^{69,70}$. We also find that the addition of both $\mathrm{Mn}$ and $\mathrm{K}$ as promoters improved the Fe-catalyst performance, directly converting $\mathrm{CO}_{2}$ into jet fuel range hydrocarbons with high efficiency.

Renewable jet fuels and the circular economy. The Circular Economy (CE) is an attractive, holistic concept gradually and steadily positioning itself as an alternative and reliable alternative to the present, "Business-as-Usual", unsustainable Linear Economy (LE) based on the "Take, make and dispose" paradigm ${ }^{71}$. Nowadays, researchers have risen to the challenge of climate change and advanced the concept of the so-called " $\mathrm{CO}_{2}$ Circular Economy", which directly integrates $\mathrm{CO}_{2}$ capture from the air (Direct Air Capture, DAC) and converts $\mathrm{CO}_{2}$ into value-added products ${ }^{81-84}$. This $\mathrm{CO}_{2}$ Circular Economy is a valid and highly powerful alternative route to simply burying huge volumes of captured $\mathrm{CO}_{2}$ underground and one in which future generations will surely expect us to have formed a major aspect of sustainable $\mathrm{CO}_{2}$ management.

Renewable jet fuels offer considerable potential in the worldwide drive for a future Sustainable Circular Economy Future for the aviation industry. The vision centres on $\mathrm{CO}_{2}$ conversion as an integral part of carbon recycling. The advances reported here offer a route out of the current, worldwide LE for jet fuels, based 
(a)

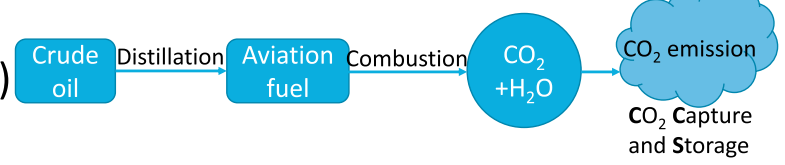

(b)

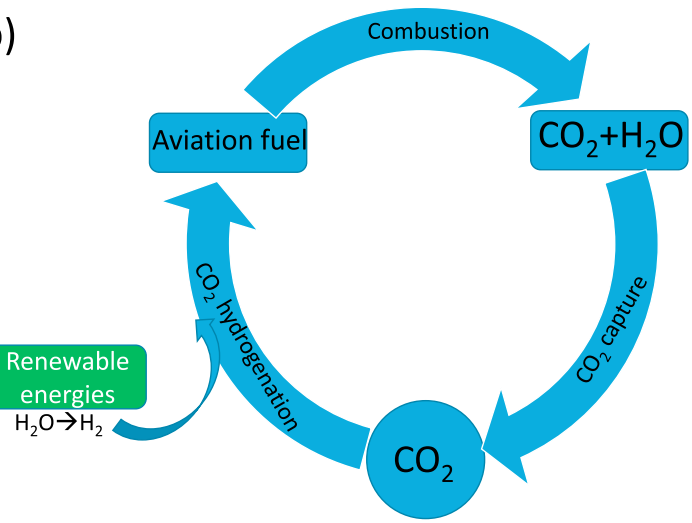

Fig. 6 llustrating the differences between (a) an Aviation Jet Fuel Linear Economy and (b) an Aviation Jet Fuel Circular Economy.

on the (present) Production-Consumption- Disposal/Emission structure, where the valuable natural resource, crude oil, is extracted, shipped across oceans, transformed into jet fuel and then combusted, with the combustion product either emitted into the atmosphere, or trapped and buried underground (through Carbon Capture and Storage). On the other hand, the CE approach is based on fundamentally-different ProductionConsumption-Recycling/Recovery structure or Carbon Capture and Utilization, where, in this case, $\mathrm{CO}_{2}$ is indeed recognized as a powerful "Resource" to be recirculated using renewable energy to yield carbon-neutral jet aviation fuel.

Obviously, our advance can contribute significantly to more sustainable fuel production process if we input renewable energy into the chain for transforming $\mathrm{CO}_{2}$ into aviation jet fuel as an additional driving force for the inevitable and urgently required transition toward a circular fuel economy centred on renewable $\mathrm{CO}_{2}$ utilization.

Within a Jet Fuel $\mathrm{CO}_{2}$ Circular Economy, the "Goods" (here the Jet Fuel) are continually reprocessed in a closed environment, which saves the natural fossil resources and preserves the environment, whilst also, of course, creating significant numbers of new jobs, new economies and new markets.

In Fig. 6, we attempt to show a comparison of the Aviation Jet Fuel Linear Economy and the Aviation Jet Fuel Circular Economy. For the latter, Green $\mathrm{H}_{2}$ is derived from renewable energy, and $\mathrm{CO}_{2}$ is directly converted to Aviation Jet Fuel using our novel catalysts with $\mathrm{CO}_{2}$ captured from the atmosphere ("Air Capture"). Note the fundamental difference between the Jet Fuel Linear Economy, as compared to the $\mathrm{CO}_{2}$ to Jet Fuel Circular Economy, where the entire latter process is a closed loop and hence a $\mathrm{CO}_{2}$ neutral process. This $\mathrm{CO}_{2}$ Circular Economy for aviation can surely empower worldwide momentum toward not only major economic development for countries but also achieving the UN's sustainable development goals.

\section{Discussion}

A series of Fe-based catalysts were prepared by the OCM for the conversion of carbon dioxide into jet fuel range hydrocarbons. This synthetic process can be used to produce homogeneous, ultrafine and high-purity crystalline metal oxide powder catalysts. The as-prepared catalysts, following activation, showed high carbon dioxide hydrogenation activity and high jet fuel range selectivity as a consequence of the small (ca. $15 \mathrm{~nm}$ ) nanoparticle size and the presence of two catalytically active $\mathrm{Fe}$ phases that operate in tandem. The first phase corresponds to $\mathrm{Fe}_{3} \mathrm{O}_{4}$ which catalyses the conversion of carbon dioxide to $\mathrm{CO}$ via the RWGS reaction whilst the second active $\mathrm{Fe}$ phase $\left(\chi-\mathrm{Fe}_{5} \mathrm{C}_{2}\right)$ catalyses the hydrogenation of $\mathrm{CO}$ through the Fischer-Tropsch process.

This catalytic process provides an attractive route not only to mitigate carbon dioxide emissions but also to produce renewable and sustainable jet fuel. The recycling of carbon dioxide as a carbon source for both fuels and high-value chemicals offers considerable potential for both the aviation and petrochemical industries. It also represents a significant social advance; thus, instead of consuming fossil crude oil, jet aviation fuels and petrochemical starting compounds are produced from a valuable and renewable raw material, namely, carbon dioxide. These advances highlight carbon dioxide recycling and resource conservation as an important, pivotal aspect of greenhouse gas management and sustainable development. This, then, is the vision for the route to achieving net-zero carbon emissions from aviation; a fulcrum of a future global zero-carbon aviation sector.

\section{Methods}

Catalyst preparation. Catalysts were prepared by the OCM method; citric acid was used as the organic compound. Typically, a Fe-Mn-K catalyst was prepared from citric acid monohydrate (99\%, Sigma-Aldrich), Iron (III) Nitrate nonahydrate (98\%, Sigma-Aldrich), Manganese(II) nitrate tetrahydrate (97\%, Sigma-Aldrich) and potassium nitrate (99\%, Sigma-Aldrich), in a molar ratio of citric acid: ( $\mathrm{Fe}$ (or $\mathrm{Co})+\mathrm{Mn}+\mathrm{K})=2$, and a weight ratio of ( $\mathrm{Fe}$ - and $\mathrm{Mn}$ - and $\mathrm{K}$-precursors + citric acid)/water $=2: 1$. This initial mixture was stirred to form a homogeneous aqueous solution and heated at $50^{\circ} \mathrm{C}$ for $1-2 \mathrm{~h}$ to obtain a citric acid-based slurry. This paste was then ignited at $350^{\circ} \mathrm{C}$ in the air for $4 \mathrm{~h}$ to produce a carbon-free powder.

Catalyst samples with different first-row transition metal $(\mathrm{Mn}, \mathrm{Cu}, \mathrm{Zn})$ promoters were also prepared using the same method; $\mathrm{Fe}-\mathrm{Cu}-\mathrm{K}$ and $\mathrm{Fe}-\mathrm{Zn}-\mathrm{K}$ catalysts were prepared using copper (II) nitrate trihydrate (99-104\%, SigmaAldrich), and zinc nitrate hexahydrate (98\%, Sigma-Aldrich) as transition metal precursors respectively. Similarly, catalysts with different Fe-Mn-Li, Fe-Mn-Na, and $\mathrm{Fe}-\mathrm{Mn}-\mathrm{Cs}$ base metal promoters were prepared using lithium carbonate $(99 \%$ Sigma-Aldrich), sodium carbonate (99.6\%, Acros Organics) and cesium carbonate (99\%, Sigma-Aldrich), respectively. Typically, the molar ratio of Fe: transit metal: base metal used was 10:1:1

$\mathrm{Fe}-\mathrm{Mn}-\mathrm{K}$ catalysts were also prepared using other organic compounds other than citric acid, specifically; urea (Bio-Reagent, Sigma-Aldrich), tannic acid (ACS reagent, Sigma-Aldrich), Ethylenediamine Tetraacetic Acid (EDTA, 99.5\%, Fisher Scientific), oxalic acid (99.0\%, Sigma-Aldrich), Nitrilotriacetic acid (NTA, 99\%, Sigma-Aldrich), Diethylenetriaminepentaacetic acid (DTPA, 98\%, Sigma-Aldrich), tartaric acid (99.5\%, Sigma-Aldrich), N-(2-Hydroxyethyl) ethylenediamine-N,N', N'-triacetic acid (HEDTA,98\%, Sigma-Aldrich), salicylic acid (99.0\%, SigmaAldrich). In all discussions catalysts were prepared with citric acid as the organic compound unless otherwise stated.

Catalysts performance evaluation. $\mathrm{CO}_{2}$ hydrogenation experiments were carried out in a stainless steel fixed bed reactor with an inner diameter of $1.0 \mathrm{~cm}$ (Zhixiang Blue Evaluation Equipment Technology) with a typical $2.0 \mathrm{~g}$ catalyst load. Prior to the reaction, the catalyst was in situ reduced with syngas $\left(\mathrm{H}_{2}: \mathrm{CO}=2: 1\right)$ at atmospheric pressure, with a GHSV (gas hourly space velocity) of $1000 \mathrm{~mL} \mathrm{~g}^{-1} \mathrm{~h}^{-1}$, at $320^{\circ} \mathrm{C}$ for $24 \mathrm{~h}$. Following reactor cooling to below $50^{\circ} \mathrm{C}$, a mixture of gas with an $\mathrm{H}_{2} / \mathrm{CO}_{2}$ ratio of 3 and $\mathrm{N}_{2}$ (as an internal standard gas) was introduced at a gas flow of $40 \mathrm{~mL} \mathrm{~min}-1$ (GSVH $\left.=2400 \mathrm{~mL} \mathrm{~g}^{-1} \mathrm{~h}^{-1}\right)$. The reactor was then heated at a rate of $2^{\circ} \mathrm{C} / \mathrm{min}$ to $300^{\circ} \mathrm{C}$. The reaction pressure was fixed at $10 \mathrm{bar}(1 \mathrm{MPa})$ using a back pressure regulator. The effluent gaseous products were analysed using an online Gas Chromatograph (Perkin Elmer Clarus 580 GC) with flame ionization (FID) and thermal conductivity detectors (TCD), and the collected liquid products were analysed by Gas Chromatograph Mass Spectrometry (SHIMADZU GCMSQP2010 SE).

The $\mathrm{CO}_{2}$ and $\mathrm{H}_{2}$ conversion and product selectivity's were calculated from the following relationships:

$$
\begin{gathered}
\mathrm{CO}_{2} \text { conversion }=\frac{\mathrm{CO}_{2, \text { inlet }}-\frac{\mathrm{N}_{2 \text { inlet }}}{\mathrm{N}_{2 \text { outlet }}} \times \mathrm{CO}_{2, \text { outlet }}}{\mathrm{CO}_{2, \text { inlet }}} \times 100 \% \\
\mathrm{H}_{2} \text { conversion }=\frac{\mathrm{H}_{2 \text { inlet }}-\frac{\mathrm{N}_{2 \text { inlet }}}{\mathrm{N}_{2 \text { outlet }}} \times \mathrm{H}_{2 \text { outlet }}}{\mathrm{H}_{2 \text { inlet }}} \times 100 \%
\end{gathered}
$$




$$
\begin{aligned}
& \mathrm{CO} \text { yield }=\frac{\frac{\mathrm{N}_{2 \text { inlet }}}{\mathrm{N}_{2 \text { outlet }}} \times \mathrm{CO}_{\text {outlet }}}{\mathrm{CO}_{2, \text { inlet }}} \times 100 \% \\
& \text { CO selectivity }=\frac{\mathrm{CO} \text { yield }}{\mathrm{CO}_{2} \text { conversion }} \times 100 \% \\
& \mathrm{C}_{\mathrm{n}} \mathrm{H}_{\mathrm{m}} \text { yield }=\frac{\mathrm{n} \times \frac{\mathrm{N}_{2 \text { inlet }}}{\mathrm{N}_{2 \text { outlet }}} \times \mathrm{C}_{\mathrm{n}} \mathrm{H}_{\mathrm{m}} \text { outlet }}{\mathrm{CO}_{2, \text { inlet }}} \times 100 \%(\mathrm{n}=1,2,3,4) \\
& \mathrm{C}_{5+} \text { yield }=\left(\mathrm{CO}_{2} \text { conversion }-\mathrm{CO} \text { yield }-\sum_{n=1}^{4} \mathrm{C}_{\mathrm{n}} \mathrm{H}_{\mathrm{m}} \text { yield }\right) \times 100 \% \\
& \text { selectivity in hydrocarbons }=\frac{\mathrm{C}_{\mathrm{n}} \mathrm{H}_{\mathrm{m}} \text { yield }}{\mathrm{CO}_{2} \text { conversion } \times(1-\mathrm{CO} \text { selectivity })} \times 100 \%
\end{aligned}
$$

The selectivity of oxygenates (mainly alcohols) was not further considered in this study as it was below $1.0 \%$.

Catalyst characterization. Powder XRD analyses of catalysts used a $\mathrm{Cu} \mathrm{Ka}$ $(0.15418 \mathrm{~nm}) \mathrm{X}$-ray source $(25 \mathrm{kV}, 40 \mathrm{~mA})$ in a Bruker D8 Advance diffractometer. Diffraction patterns were recorded over a $10-80^{\circ} 2 \theta$ angular range using a step size of $0.02^{\circ}$.

X-ray photoelectron spectroscopy (XPS) of samples was performed using a Thermo Fisher Scientific Nexsa spectrometer. Samples were analysed using a micro-focused monochromatic Al X-ray source (72 W) over an area of $\sim 400 \times 200$ $\mu \mathrm{m}^{2}$. Data were recorded at pass energies of $150 \mathrm{eV}$ for survey scans and $40 \mathrm{eV}$ for high-resolution scans with 1 and $0.1 \mathrm{eV}$ step sizes respectively. Charge neutralisation was achieved using a combination of low energy electrons and argon ions. The resulting spectra were analyzed using Casa XPS peak fitting software and sample charging corrected using the $\mathrm{C} 1 \mathrm{~s}$ signal at $284.8 \mathrm{eV}$ as a reference.

Thermogravimetric analysis (TGA) was used to characterise the resulting carbon depositions in our catalyst samples. A TPO was carried out to determine the thermal stability of the produced carbons. The sample was heated from room temperature to $1000^{\circ} \mathrm{C}$ at a heating rate of $10^{\circ} \mathrm{C} / \mathrm{min}$ under an air atmosphere with a flow rate of $100 \mathrm{ml} / \mathrm{min}$.

The catalyst morphology was characterised using scanning electron microscopy (SEM JEOL 840F) at an accelerating voltage of $6.0 \mathrm{kV}$.

High-resolution scanning transmission electron microscopy (STEM) annular dark field (ADF) and bright field (BF) images were obtained using a probe corrected JEOL ARM200F at the David Cockayne Centre for Electron Microscopy operated at $200 \mathrm{kV}$ with ADF inner and outer detector angles of $28-104.36 \mathrm{mrad}$, respectively, a $13.20 \mathrm{mrad} \mathrm{BF}$ outer angle, and a $14 \mathrm{mrad}$ convergence semi-angle.

Reporting summary. Further information on research design is available in the Nature Research Reporting Summary linked to this article.

\section{Data availability}

The authors declare that the main data supporting the findings of this study are contained within the paper and its associated Supplementary Information. All other relevant data are available from the corresponding author upon reasonable request.

Received: 6 July 2020; Accepted: 20 November 2020;

Published online: 22 December 2020

\section{References}

1. Tian, H. et al. The terrestrial biosphere as a net source of greenhouse gases to the atmosphere. Nature 531, 225 (2016).

2. Bello, B. Captured $\mathrm{CO}_{2}$ to grow microalgae for bio-jet fuel production. (UKCCSC Winter School, University of Cambridge, Cambridge, UK, 2012).

3. Hari, T. K., Yaakob, Z. \& Binitha, N. N. Aviation biofuel from renewable resources: routes, opportunities and challenges. Renew. Sust. Energ. Rev. 42, 1234-1244 (2015).

4. Kallio, P., Pásztor, A., Akhtar, M. K. \& Jones, P. R. Renewable jet fuel. Curr. Opin. Biotechnol. 26, 50-55 (2014).

5. Liu, G., Yan, B. \& Chen, G. Technical review on jet fuel production. Renew. Sust. Energ. Rev. 25, 59-70 (2013).

6. Gnanamani, M. K. et al. Hydrogenation of carbon dioxide over $\mathrm{Co}-\mathrm{Fe}$ bimetallic catalysts. ACS Catal. 6, 913-927 (2016).

7. Jiang, Z., Xiao, T., Kuznetsov, V. á \& Edwards, P. P. Turning carbon dioxide into fuel. Phil. Trans. R. Soc. A 368, 3343-3364 (2010).
8. Li, S. et al. Tuning the selectivity of catalytic carbon dioxide hydrogenation over iridium/cerium oxide catalysts with a strong metal-support interaction. Angew. Chem. Int. Ed. 56, 10761-10765 (2017).

9. Schneidewind, J., Adam, R., Baumann, W., Jackstell, R. \& Beller, M. Lowtemperature hydrogenation of carbon dioxide to methanol with a homogeneous cobalt catalyst. Angew. Chem. Int. Ed. 56, 1890-1893 (2017).

10. Song, Q.-W., Zhou, Z.-H. \& He, L.-N. Efficient, selective and sustainable catalysis of carbon dioxide. Green Chem. 19, 3707-3728 (2017).

11. Wang, W., Wang, S., Ma, X. \& Gong, J. Recent advances in catalytic hydrogenation of carbon dioxide. Chem. Soc. Rev. 40, 3703-3727 (2011)

12. Yang, $\mathrm{H}$. et al. A review of the catalytic hydrogenation of carbon dioxide into value-added hydrocarbons. Catal. Sci. Technol. 7, 4580-4598 (2017).

13. Zhang, X. et al. Product selectivity in plasmonic photocatalysis for carbon dioxide hydrogenation. Nat. Commun. 8, 14542 (2017).

14. Asadi, M. et al. Nanostructured transition metal dichalcogenide electrocatalysts for $\mathrm{CO}_{2}$ reduction in ionic liquid. Science 353, 467-470 (2016).

15. Buelens, L. C., Galvita, V. V., Poelman, H., Detavernier, C. \& Marin, G. B. Super-dry reforming of methane intensifies $\mathrm{CO}_{2}$ utilization via Le Chatelier's principle. Science 354, 449-452 (2016)

16. Choi, Y. H. et al. Carbon dioxide Fischer-Tropsch synthesis: A new path to carbon-neutral fuels. Appl. Catal. B 202, 605-610 (2017).

17. Kattel, S., Ramírez, P. J., Chen, J. G., Rodriguez, J. A. \& Liu, P. Active sites for $\mathrm{CO}_{2}$ hydrogenation to methanol on $\mathrm{Cu} / \mathrm{ZnO}$ catalysts. Science 355, 1296-1299 (2017).

18. Klankermayer, J. \& Leitner, W. Love at second sight for $\mathrm{CO}_{2}$ and $\mathrm{H}_{2}$ in organic synthesis. Science 350, 629-630 (2015).

19. Mariano, R. G., McKelvey, K., White, H. S. \& Kanan, M. W. Selective increase in $\mathrm{CO}_{2}$ electroreduction activity at grain-boundary surface terminations. Science 358, 1187-1192 (2017).

20. Satthawong, R., Koizumi, N., Song, C. \& Prasassarakich, P. Bimetallic Fe-Co catalysts for $\mathrm{CO}_{2}$ hydrogenation to higher hydrocarbons. J. $\mathrm{CO} 2$ Util.J. $\mathrm{CO} 2$ Util. 3, 102-106 (2013)

21. Dowson, G. R. \& Styring, P. Demonstration of $\mathrm{CO}_{2}$ conversion to synthetic transport fuel at flue gas concentrations. Front. Energy Res. 5, 26 (2017)

22. Michailos, S., McCord, S., Sick, V., Stokes, G. \& Styring, P. Dimethyl ether synthesis via captured $\mathrm{CO}_{2}$ hydrogenation within the power to liquids concept: a techno-economic assessment. Energy Convers. Manag. 184, 262-276 (2019)

23. Vogt, C. et al. Understanding carbon dioxide activation and carbon-carbon coupling over nickel. Nat. Commun. 10, 5330 (2019).

24. Wang, L. et al. Silica accelerates the selective hydrogenation of $\mathrm{CO}_{2}$ to methanol on cobalt catalysts. Nat. Commun. 11, 1033 (2020).

25. Chen, L., Zhang, L., Xia, S. \& Sun, F. Entropy generation minimization for $\mathrm{CO}_{2}$ hydrogenation to light olefins. Energy 147, 187-196 (2018).

26. $\mathrm{Hu}, \mathrm{B}$. et al. Selective hydrogenation of $\mathrm{CO}_{2}$ and $\mathrm{CO}$ to useful light olefins over octahedral molecular sieve manganese oxide supported iron catalysts. Appl. Catal. B 132, 54-61 (2013).

27. $\mathrm{Hu}$, S. et al. Hydrothermally stable MOFs for $\mathrm{CO}_{2}$ hydrogenation over ironbased catalyst to light olefins. J. CO2 Util. 15, 89-95 (2016).

28. Liang, B. et al. Mn decorated $\mathrm{Na} / \mathrm{Fe}$ catalysts for $\mathrm{CO}_{2}$ hydrogenation to light olefins. Catal. Sci. Technol. 9, 456-464 (2019).

29. Zhang, J. et al. Selective formation of light olefins from $\mathrm{CO}_{2}$ hydrogenation over Fe-Zn-K catalysts. J. CO2 Util. 12, 95-100 (2015).

30. Boutin, E. et al. Aqueous Electrochemical Reduction of Carbon Dioxide and Carbon Monoxide into Methanol with Cobalt Phthalocyanine. Angew. Chem. Int. Ed. (2019).

31. Gusain, R., Kumar, P., Sharma, O. P., Jain, S. L. \& Khatri, O. P. Reduced graphene oxide- $\mathrm{CuO}$ nanocomposites for photocatalytic conversion of $\mathrm{CO}_{2}$ into methanol under visible light irradiation. Appl. Catal. B 181, 352-362 (2016).

32. Kothandaraman, J., Goeppert, A., Czaun, M., Olah, G. A. \& Prakash, G. S. Conversion of $\mathrm{CO}_{2}$ from air into methanol using a polyamine and a homogeneous ruthenium catalyst. J. Am. Chem. Soc. 138, 778-781 (2016).

33. Frontera, P., Macario, A., Ferraro, M. \& Antonucci, P. Supported catalysts for $\mathrm{CO}_{2}$ methanation: a review. Catalysts 7, 59 (2017)

34. Wang, F. et al. Active site dependent reaction mechanism over $\mathrm{Ru} / \mathrm{CeO}_{2}$ catalyst toward $\mathrm{CO}_{2}$ methanation. J. Am. Chem. Soc. 138, 6298-6305 (2016).

35. Xu, J. et al. Influence of pretreatment temperature on catalytic performance of rutile $\mathrm{TiO}_{2}$-supported ruthenium catalyst in $\mathrm{CO}_{2}$ methanation. J. Catal. 333, 227-237 (2016)

36. Liu, B. et al. Novel sour water gas shift catalyst (SWGS) for lean steam to gas ratio applications. Fuel Process. Technol. 134, 65-72 (2015).

37. Upadhye, A. A. et al. Plasmon-enhanced reverse water gas shift reaction over oxide supported Au catalysts. Catal. Sci. Technol. 5, 2590-2601 (2015).

38. Bahruji, $\mathrm{H}$. et al. Hydrogenation of $\mathrm{CO}_{2}$ to dimethyl ether over Brønsted acidic PdZn catalysts. Ind. Eng. Chem. Res. 57, 6821-6829 (2018). 
39. Birdja, Y. Y. et al. Advances and challenges in understanding the electrocatalytic conversion of carbon dioxide to fuels. Nat. Energy 4, 732-745 (2019).

40. Xia, C. et al. Continuous production of pure liquid fuel solutions via electrocatalytic $\mathrm{CO}_{2}$ reduction using solid-electrolyte devices. Nat. Energy 4, 1-10 (2019).

41. Ye, R.-P. et al. $\mathrm{CO}_{2}$ hydrogenation to high-value products via heterogeneous catalysis. Nat. Commun. 10, 5698 (2019).

42. Gao, P. et al. Direct conversion of $\mathrm{CO}_{2}$ into liquid fuels with high selectivity over a bifunctional catalyst. Nat. Chem. 9, 1019 (2017).

43. Wang, W., Jiang, X., Wang, X. \& Song, C. Fe-Cu bimetallic catalysts for selective $\mathrm{CO}_{2}$ hydrogenation to olefin-rich $\mathrm{C}_{2+}$ hydrocarbons. Ind. Eng. Chem. Res. 57, 4535-4542 (2018).

44. Wei, J. et al. Directly converting $\mathrm{CO}_{2}$ into a gasoline fuel. Nat. commun. 8, 15174 (2017).

45. Yao, B. et al. Thermodynamic study of hydrocarbon synthesis from carbon dioxide and hydrogen. Greenhouse Gas. Sci. Technol 7, 942-957 (2017).

46. Marlin, D. S., Sarron, E. \& Sigurbjörnsson, Ó. Process advantages of direct $\mathrm{CO}_{2}$ to methanol synthesis. Front. Chem. 6, 446 (2018).

47. Vogt, C., Monai, M., Kramer, G. J. \& Weckhuysen, B. M. The renaissance of the Sabatier reaction and its applications on Earth and in space. Nat. Catal. 2, 188-197 (2019).

48. Xiao, T. et al. The Catalyst Selectivity Index (CSI): a framework and metric to assess the impact of catalyst efficiency enhancements upon energy and $\mathrm{CO}_{2}$ footprints. Top. Catal. 58, 682-695 (2015).

49. Alayat, A., Mcllroy, D. \& McDonald, A. G. Effect of synthesis and activation methods on the catalytic properties of silica nanospring (NS)-supported iron catalyst for Fischer-Tropsch synthesis. Fuel Process. Technol. 169, 132-141 (2018).

50. Beasley, C., Gnanamani, M. K., Hamdeh, H. H., Martinelli, M. \& Davis, B. H. Effect of gallium additions on reduction, carburization and Fischer-Tropsch activity of iron catalysts. Catal. Lett. 148, 1920-1928 (2018).

51. Ding, M. et al. Study on reduction and carburization behaviors of iron phases for iron-based Fischer-Tropsch synthesis catalyst. Appl. Energy 160, 982-989 (2015).

52. Mirzaei, A. A., Sarani, R., Azizi, H. R., Vahid, S. \& Torshizi, H. O. Kinetics modeling of Fischer-Tropsch synthesis on the unsupported Fe-Co-Ni (ternary) catalyst prepared using co-precipitation procedure. Fuel 140, 701-710 (2015).

53. Nakhaei Pour, A., Khodabandeh, H., Izadyar, M. \& Housaindokht, M. R. Mechanistic double ASF product distribution study of Fischer-Tropsch synthesis on precipitated iron catalyst. J. Nat. Gas Sci. Eng. 15, 53-58 (2013).

54. Yang, C., Zhao, H., Hou, Y. \& Ma, D. $\mathrm{Fe}_{5} \mathrm{C}_{2}$ nanoparticles: a facile bromideinduced synthesis and as an active phase for Fischer-Tropsch synthesis. J. Am. Chem. Soc. 134, 15814-15821 (2012).

55. Liu, B. et al. Unravelling the new roles of $\mathrm{Na}$ and $\mathrm{Mn}$ promoter in $\mathrm{CO}_{2}$ hydrogenation over $\mathrm{Fe}_{3} \mathrm{O}_{4}$-based catalysts for enhanced selectivity to light aolefins. ChemCatChem 10, 4718-4732 (2018).

56. Liu, J. et al. Direct transformation of carbon dioxide to value-added hydrocarbons by physical mixtures of $\mathrm{Fe}_{5} \mathrm{C}_{2}$ and $\mathrm{K}$-modified $\mathrm{Al}_{2} \mathrm{O}_{3}$. Ind. Eng. Chem. Res. 57, 9120-9126 (2018)

57. Zhai, P. et al. Highly tunable selectivity for syngas-derived alkenes over zinc and sodium-modulated $\mathrm{Fe}_{5} \mathrm{C}_{2}$ catalyst. Angew. Chem. Int. Ed. 55, 9902-9907 (2016).

58. Liang, B. et al. Effect of $\mathrm{Na}$ promoter on Fe-based catalyst for $\mathrm{CO}_{2}$ hydrogenation to alkenes. ACS Sustain. Chem. Eng. 7, 925-932 (2018).

59. Ronda-Lloret, M., Rothenberg, G. \& Shiju, N. R. A critical look at direct catalytic hydrogenation of carbon dioxide to olefins. ChemSusChem 12, 3896-3914 (2019).

60. Wang, S. et al. Iron-potassium on single-walled carbon nanotubes as efficient catalyst for $\mathrm{CO}_{2}$ hydrogenation to heavy olefins. ACS Catal. 10, 6389-6401 (2020).

61. Wilson, D. \& Langell, M. XPS analysis of oleylamine/oleic acid capped $\mathrm{Fe}_{3} \mathrm{O}_{4}$ nanoparticles as a function of temperature. Appl. Surf. Sci. 303, 6-13 (2014).

62. Bahome, M. C., Jewell, L. L., Hildebrandt, D., Glasser, D. \& Coville, N. J. Fischer-Tropsch synthesis over iron catalysts supported on carbon nanotubes. Appl. Catal., A 287, 60-67 (2005).

63. Lu, Y. et al. Fischer-Tropsch synthesis of olefin-rich liquid hydrocarbons from biomass-derived syngas over carbon-encapsulated iron carbide/iron nanoparticles catalyst. Fuel 193, 369-384 (2017).

64. Han, L., Wang, C., Zhao, G., Liu, Y. \& Lu, Y. Microstructured Al-fiber@ meso$\mathrm{Al}_{2} \mathrm{O}_{3} @ \mathrm{Fe}-\mathrm{Mn}-\mathrm{K}$ Fischer-Tropsch catalyst for lower olefins. AIChE J. 62, 742-752 (2016).

65. Li, T. et al. Effect of manganese on an iron-based Fischer-Tropsch synthesis catalyst prepared from ferrous sulfate. Fuel 86, 921-928 (2007)

66. Gao, X. et al. Effects of zinc on Fe-based catalysts during the synthesis of light olefins from the Fischer-Tropsch process. Chinese J. Catal. 37, 510-516 (2016).
67. Yang, S. et al. Linear $\alpha$-olefin production with Na-promoted Fe-Zn catalysts via Fischer-Tropsch synthesis. RSC Adv. 9, 14176-14187 (2019).

68. Chernavskii, P. A. et al. Influence of copper and potassium on the structure and carbidisation of supported iron catalysts for Fischer-Tropsch synthesis. Catal. Sci. Technol. 7, 2325-2334 (2017).

69. Lohitharn, N. \& Goodwin, J. G. Jr Effect of K promotion of Fe and FeMn Fischer-Tropsch synthesis catalysts: analysis at the site level using SSITKA. J. Catal. 260, 7-16 (2008).

70. Yang, Y., Xiang, H.-W., Xu, Y.-Y., Bai, L. \& Li, Y.-W. Effect of potassium promoter on precipitated iron-manganese catalyst for Fischer-Tropsch synthesis. Appl. Catal., A 266, 181-194 (2004).

71. An, X. et al. Comparative study of iron-based Fischer-Tropsch synthesis catalyst promoted with potassium or sodium. Catal. Commun. 8, 1957-1962 (2007).

72. Wu, X. et al. Li-decorated Fe-Mn nanocatalyst for high-temperature Fischer-Tropsch synthesis of light olefins. Fuel 257, 116101 (2019).

73. González-Cortés, S. L. \& Imbert, F. E. Fundamentals, properties and applications of solid catalysts prepared by solution combustion synthesis (SCS). Appl. Catal., A 452, 117-131 (2013).

74. Toniolo, J. C., Lima, M. D., Takimi, A. S. \& Bergmann, C. P. Synthesis of alumina powders by the glycine-nitrate combustion process. Mater. Res. Bull. 40, 561-571 (2005).

75. Purohit, R., Sharma, B., Pillai, K. \& Tyagi, A. Ultrafine ceria powders via glycine-nitrate combustion. Mater. Res. Bull. 36, 2711-2721 (2001).

76. Zhang, Z. et al. Synthesis and catalytic properties of $\mathrm{Ce}_{0.6} \mathrm{Zr}_{0.4} \mathrm{O}_{2}$ solid solutions in the oxidation of soluble organic fraction from diesel engines. Appl. Catal. B 76, 335-347 (2007).

77. Park, H. et al. Selective formation of Hägg iron carbide with $g-\mathrm{C}_{3} \mathrm{~N}_{4}$ as a sacrificial support for highly active Fischer-Tropsch synthesis. ChemCatChem 7, 3488-3494 (2015).

78. Gracia, J. M., Prinsloo, F. F. \& Niemantsverdriet, J. W. Mars-van Krevelen-like mechanism of CO hydrogenation on an iron carbide surface. Catal. Lett. 133, 257 (2009).

79. Ordomsky, V., Legras, B., Cheng, K., Paul, S. \& Khodakov, A. The role of carbon atoms of supported iron carbides in Fischer-Tropsch synthesis. Catal. Sci. Technol. 5, 1433-1437 (2015).

80. Kirchner, J., Baysal, Z. \& Kureti, S. Activity and structural changes of Fe-based catalysts during $\mathrm{CO}_{2}$ hydrogenation towards $\mathrm{CH}_{4}$-a mini review. Chem CatChem 12, 981-988 (2020).

81. Goeppert, A., Czaun, M., Jones, J.-P., Prakash, G. S. \& Olah, G. A. Recycling of carbon dioxide to methanol and derived products-closing the loop. Chem. Soc. Rev. 43, 7995-8048 (2014)

82. Nocito, F. \& Dibenedetto, A. Atmospheric $\mathrm{CO}_{2}$ mitigation technologies: carbon capture utilization and storage. Curr. Opin. Green Sustain. Chem. 21, 34-43 (2020).

83. Ampelli, C., Perathoner, S. \& Centi, G. $\mathrm{CO}_{2}$ utilization: an enabling element to move to a resource-and energy-efficient chemical and fuel production. Phil. Trans. R. Soc. A 373, 20140177 (2015).

84. Falcinelli, S. Fuel production from waste $\mathrm{CO}_{2}$ using renewable energies. Catal. Today 348, 95-101 (2020).

85. Wei, J. et al. New insights into the effect of sodium on $\mathrm{Fe}_{3} \mathrm{O}_{4}$-based nanocatalysts for $\mathrm{CO}_{2}$ hydrogenation to light olefins. Catal. Sci. Technol. 6, 4786-4793 (2016)

86. Wei, J. et al. Catalytic hydrogenation of $\mathrm{CO}_{2}$ to isoparaffins over Fe-based multifunctional catalysts. ACS Catal. 8, 9958-9967 (2018).

87. Albrecht, $\mathrm{M}$. et al. Unexpectedly efficient $\mathrm{CO}_{2}$ hydrogenation to higher hydrocarbons over non-doped $\mathrm{Fe}_{2} \mathrm{O}_{3}$. Appl. Catal. B 204, 119-126 (2017).

88. He, Z. et al. Synthesis of liquid fuel via direct hydrogenation of $\mathrm{CO}_{2}$. Proc. Natl Acad. Sci. USA 116, 12654-12659 (2019).

89. Fujiwara, M., Kieffer, R., Ando, H. \& Souma, Y. Development of composite catalysts made of $\mathrm{Cu}-\mathrm{Zn}-\mathrm{Cr}$ oxide/zeolite for the hydrogenation of carbon dioxide. Appl. Catal., A 121, 113-124 (1995).

90. Wang, X. et al. Synthesis of isoalkanes over a core (Fe-Zn-Zr)-shell (zeolite) catalyst by $\mathrm{CO}_{2}$ hydrogenation. Chem. Commun. 52, 7352-7355 (2016).

\section{Acknowledgements}

The authors thank EPSRC (Grant EP/N009924/1), Rolls-Royce and KACST, Saudi Arabia for financial support and encouragement. EPSRC grant code, EP/K040375/1, for the South of England Analytical Electron Microscope. XPS data collection was performed at the EPSRC National Facility for XPS ('HarwellXPS'), operated by Cardiff University and UCL, under contract No. PR16195.

\section{Author contributions}

B.Y. wrote the manuscript with input from all the authors. B.Y., T.X., and P.P.E. conceived this study. B.Y. designed the experiments, performed the catalysts synthesis, catalysts evaluation, and X-ray diffraction and data analysis. O.A.M performed the STEM, X.J. 
performed the TEM, S. G. performed the XPS. B.Y., T.X., O.A.M., X.J., S. G-C., S. G., A.I.K., J.R.D., H.A.A., S.M.A., P.J.D., G.P.O., J.M.T. and P.P.E. contributed to analysis and discussion on the data, revising the article for intellectual content. T.X. and P.P.E. supervised the research. We dedicate this contribution to the memory of Sir John Meurig Thomas, FRS.

\section{Competing interests}

The authors (B.Y., T.X., and P.P.E.) have a patent application: Iron-manganese based catalyst, catalyst precursor and catalytic process, WO 2020/201749, B.Y., P.P.E., and T.X., related to this research. All other authors declare no competing interests.

\section{Additional information}

Supplementary information is available for this paper at https://doi.org/10.1038/s41467020-20214-z.

Correspondence and requests for materials should be addressed to T.X. or P.P.E.

Peer review information Nature communications thanks Vitaly Ordomsky, and the other, anonymous, reviewer(s) for their contribution to the peer review of this work. Peer reviewer reports are available.
Reprints and permission information is available at http://www.nature.com/reprint

Publisher's note Springer Nature remains neutral with regard to jurisdictional claims in published maps and institutional affiliations.

(c) (i)

Open Access This article is licensed under a Creative Commons Attribution 4.0 International License, which permits use, sharing, adaptation, distribution and reproduction in any medium or format, as long as you give appropriate credit to the original author(s) and the source, provide a link to the Creative Commons license, and indicate if changes were made. The images or other third party material in this article are included in the article's Creative Commons license, unless indicated otherwise in a credit line to the material. If material is not included in the article's Creative Commons license and your intended use is not permitted by statutory regulation or exceeds the permitted use, you will need to obtain permission directly from the copyright holder. To view a copy of this license, visit http://creativecommons.org/ licenses/by/4.0/.

(C) The Author(s) 2020 